WISSENSCHAFTSZENTRUM BERLIN FÜR SOZIALFORSCHUNG

SOCIAL SCIENCE RESEARCH CENTER BERLIN

\author{
Albert Banal-Estañol * \\ Inés Macho-Stadler ** \\ Jo Seldeslachts ***
}

\title{
Mergers, Investment Decisions and Internal Organisation
}

\author{
* University of Western Ontario \\ ** Universitat Autònoma de Barcelona \\ *** WZB - Wissenschaftszentrum Berlin
}

SP II $2004-13$

November 2004

ISSN Nr. $0722-6748$

Research Area

Markets and Political Economy

Research Unit

Competitiveness and Industrial Change
Forschungsschwerpunkt

Markt und politische Ökonomie

Abteilung

Wettbewerbsfähigkeit und industrieller Wandel 
Zitierweise/Citation:

Albert Banal-Estañol, Inés Macho-Stadler and Jo

Seldeslachts, Mergers, Investment Decisions and Internal

Organisation, Discussion Paper SP II 2004 - 13,

Wissenschaftszentrum Berlin, 2004.

Wissenschaftszentrum Berlin für Sozialforschung gGmbH,

Reichpietschufer 50, 10785 Berlin, Germany, Tel. (030) 25491 - 0

Internet: www.wz-berlin.de 


\section{Mergers, Investment Decisions and Internal Organisation*}

by Albert Banal-Estañol, Inés Macho-Stadler, and Jo Seldeslachts

We analyse the effects of investment decisions and firms' internal organisation on the efficiency and stability of horizontal mergers. In our framework synergies are endogenous and there might be internal conflict within merged firms. We show that often stable mergers do not lead to more efficiency and may even lead to efficiency losses. These mergers lead to lower welfare, suggesting that a regulator should be careful in assuming that possible efficiency gains of a merger will be effectively realised. Moreover, the paper offers a possible explanation for merger failures.

Keywords: Horizontal Mergers, Investment, Efficiency gains, Internal Conflict.

JEL Classification: L22, D43.

We are grateful to Margarida Catalao, Hans Degryse, Ramón Faulí, Xavier Martínez-Giralt, Pau Olivella, David Pérez-Castrillo, Jordi Sempere, the editor and two anonymous referees for valuable discussions and helpful comments. We have also benefited from the comments of seminar participants at UAB (Barcelona), RES Easter School 2002 (Birmingham), Ecole de Printemps 2002 (Aix-en-Provence), EARIE 2002 (Madrid), SAE 2002 (Salamanca), Erasmus University (Rotterdam), CESifo IO Conference 2003 (Munchen) and SMYE 2003 (Leuven). Financial support from Ministerio de Ciencia y Tecnología (BEC2000-0172, BEC2003-01132), Generalitat (Barcelona Economics - CREA and 2001SGR-00162), the Interuniversity College voor Management Science Belgium and the EC 5th Framework Programme Research Training Network (HPRN-CT-2002-00224) is gratefully acknowledged.

Albert Banal-Estañol, Department of Economics, University of Western Ontario, London, Ontario, Canada N6A 5C2. E-mail: abanales@uwo.ca

Inés Macho-Stadler, Departament d'Economia i d'Història Econòmica, Edifici B, Universitat Autònoma de Barcelona, 08193 Bellaterra (Barcelona), Spain. Email: ines.macho@uab.es

Jo Seldeslachts, Social Science Research Center Berlin (WZB), Reichpietschufer 50, 1010785 Berlin, Germany. Email: seldeslachts@wz-berlin.de 


\section{Fusionen, Investitionsentscheidungen und unternehmensinterne} Organisation

Wir analysieren die Auswirkungen von Investitionsentscheidungen und internen Organisationsstrukturen auf die Effizienz und Stabilität von horizontalen Firmenzusammenschlüssen. In unserer Untersuchung sind Synergien endogen und es können interne Konflikte in dem fusionierten Unternehmen auftreten. Es zeigt sich, dass "stabile" Fusionen häufig nicht zu mehr Effizienz, sondern sogar zu Effizienzverlusten führen können. Da solche Firmenzusammenschlüsse zu einer geringeren Wohlfahrt führen, sollte der Regulierer nicht ungeprüft annehmen, dass potentielle Wohlfahrtsgewinne auch immer tatsächlich erreicht werden. Außerdem bietet das Papier eine mögliche Erklärung für das Scheitern von Fusionen. 


\section{Introduction}

Mergers are common practice in many markets and their dynamics, as well as their advantages and disadvantages, are often discussed. Especially the analysis of horizontal mergers and their possible efficiency gains have been important topics in recent years (European Commission Report [6]).

Economic merger theory shows that a merger can reduce welfare by increasing market power but that it can also create efficiency gains in a variety of ways, thereby making the merger possibly welfare enhancing (see Röller et al. [24] for an overview).

This is the approach indicated by the Merger Guidelines released by the US department of Justice, which “...will not challenge a merger if efficiencies are sufficient to reverse the merger's potential to harm consumers in the relevant market, e.g. by preventing price increases in that market" (US Merger Guidelines, revised April 8, 1007, section 4). It is debatable whether the European Merger Regulation No. 4064/89 allows or not for an efficiency defence. In practice however, the European Commission (EC) has so far never used efficiency gains arguments to clear a merger. But the EC is also thinking to include specific guidelines on efficiency gains (Röller et al. [25]).

This paper broadens the theory on horizontal mergers with efficiency gains in concentrated markets. Currently all discussions on mergers are limited to exogenous efficiencies while the outcomes and policy recommendations could be different when becoming more efficient requires investment and is thus a strategic decision. In their study for the European Commission, Röller et al. [25] lament the lack of economic knowledge about the interaction of merger and investment decisions: "It is not clear how one should treat the endogenous scale economies that are an alienable aspect of concentrated industries". The possibility that a merged firm may become more efficient does not mean that these gains will be actually realised as is now widely assumed in the economics literature.

The aim is to shed more light on how merger and investment decisions interact, and look how the internal organisation of firms has an influence on these interactions. A newly merged firm brings together different management teams, which can lead to distrust and conflict and therefore possibly less investment. ${ }^{1}$ Our approach facilitates the understanding of why some

\footnotetext{
${ }^{1}$ A recent example can be found in the creation of Corus in 1999. The Anglo-Dutch group became the thirdbiggest steel company in the world, but its value has dramatically come down. The Economist (March 15th 2003) argues that the error was that Corus "failed to construct a workable model for its internal management, choosing instead to paper over the differences between the English and the Dutch systems."
} 
mergers may fail to become more efficient or even fail to happen. This allows us to pin down some pitfalls for the regulator when taking into account efficiency gains.

There exist two different strands in the literature in modelling merger formation. In the exogenous merger literature, the modeler exogenously fixes a group of firms whose members compare the benefits of going together with the benefits of staying alone. Although these models help to study the private and social incentives to merge, they do not predict the resulting market structure. Other firms cannot react to the merger and more importantly, different groups of firms may find it profitable to merge. In the more recent endogenous merger literature models, all firms are allowed to choose whether to merge or not and how to react to a merger, providing a prediction of the final market structure. This proves to be crucial in making policy recommendations and in understanding market outcomes and it is the approach we take in this paper. $^{2}$

Different approaches have been proposed to model mergers endogenously. Some papers rely on non-cooperative game theoretic solutions. ${ }^{3}$ But the theory of dynamic process of merger formation relies on arbitrary assumptions concerning the rules and the timing of the game. The alternative way we follow is to not fully describe the merger process, but to check whether a particular market structure can be the outcome of a merger process because no firm wants to change the current configuration. An industry structure is called stable if no manager or group of managers has an incentive to deviate and form a different firm. ${ }^{4}$ The backside of such a methodology is its complexity and we only allow for three managers or firms present in the market, this being the minimum number to allow for mergers with "insiders" and "outsiders". We believe however that the main effects present would not change in situations with more than three firms.

\footnotetext{
${ }^{2}$ For example, Motta and Vasconcelos [20] show that a shortsighted regulator -one that considers only one merger without anticipating future reactions of competitors- could make wrong decisions in considering only the present merger. Or, Fridolfsson and Stennek [11] show that if being an "insider" is better than being an "outsider," firms may merge to preempt their partner merging with a rival, even if this reduces profits with respect to the status quo.

${ }^{3}$ Take for example again Motta and Vasconcelos [20] who analyse a four-firm sequential merger formation game. First two firms decide upon merging and then the two remaining firms can react by going together as well. If both mergers go ahead, a monopoly market structure is considered. At each stage, a regulator can block the merger and stop the merger process.

${ }^{4}$ Other papers that also used concepts of stability in a merger framework are Barros [3] in a three-firm Cournot model for asymmetric firms and Horn and Persson [17] for any number of firms. Both papers however do not describe internal organisation issues and abstract from the sharing of the profits between merger partners.
} 
We construct thus a model of endogenous mergers with three managers, or equivalently with three management teams having aligned interests. We will use the terms "managers" and "management teams" as synonyms throughout the rest of the paper. Managers choose whom to form partnerships with while anticipating a share of the future revenues. In line with Rajan and Zingales [22], we think it is realistic to claim that the manager and not the owner is in control of many decisions that affect a firm's efficiency. ${ }^{5}$ Each manager controls some non-transferable resources, such as organisational or managerial capacities, that determine production costs. When managers are together, the resources of the new formed firm add up the resources that the participating managers control. ${ }^{6}$ This allows us to take into account efficiency gains due to the close integration of specific hard-to-trade assets owned by the merging managers, "synergies" in the terminology of Farrell and Shapiro [8].

A merged firm cannot enjoy these synergies if it fires a manager (or his team) since the fired manager would take his assets with him. This is most clear with human capital as the brought in assets. If a merger is at least partly executed to lead to synergy gains by the bringing together of hard-to-trade assets, it is not an option to dismiss a manager or his team.

However, the possibility that a merger leads to efficiency gains does not mean that these gains will be actually realised. This is because of two related factors. Firstly, the right asset investment for the firm may imply a private cost for a manager: it may leave the manager to forego private benefits. In making the relation-specific investment which benefits the firm, he may not be able to do a more market-oriented investment, increasing the value of his assets for outside use and thus more benefiting him privately. ${ }^{7}$ The idea that managers' interests are not always perfectly aligned with the interests of the firm as a whole is not a new one and is proposed by a number of authors in different forms. ${ }^{8}$

\footnotetext{
${ }^{5}$ Rajan and Zingales [22] say that the amount of surplus that a manager gets from the control of residual rights is often more contingent on him making the right specific investment than the surplus that comes from ownership. Hence, access to the resources of the firm can be a better mechanism to describe power than ownership.

${ }^{6}$ This argument is valid for all cases where the resources are complementary. The same idea is found in Bloch [4] and Goyal and Moraga-González [13], where efforts in R\&D induce a higher spillover if firms are in a joint venture.

${ }^{7}$ This is again most evident with bringing in human capital. Take the manager (or a team of workers led by a manager) who brings in specific computer knowledge. It would be in the best interest of the firm if the manager learns and develops some information system A given the specific needs of the firm, but at the moment information system B is more "hot" in the market. Thus, learning and developing system A comes at a private cost for the manager.

${ }^{8}$ Fulghieri and Rodrick [10] model internal agency activities as entrenchment: to avoid personal costs, a divisional manager can reduce the probability of his division being divested by reducing its attractiveness to
} 
Secondly, forging a common corporate goal out of two or more disparate cultures can be difficult and can even lead to less efficient and less profitable firms. Surprisingly enough, concepts such as distrust and conflict within the firm are often forgotten in the economics literature when looking at merger decisions, despite evidence indicating that they play a major role (Seabright [27]). It is said that the motivation of managers to work together in the interest of the firm comes from team spirit and trust (Kandel and Lazear [18]). But, this is exactly what is lacking in a newly merged firm. If people do not trust each other, then parties' primary objective is ensuring their personal interests, rather than sacrificing those interests entirely to the benefit of the whole firm. This need establishes and reinforces the manager's preference over the firm's (Flynn [9]). At the same time, we assume that it is not possible to write complete contracts on investment decisions, since in many circumstances, it is intrinsically hard to describe the "right" action in sufficient detail to distinguish it from many seemingly similar actions. Thus, the lack of trust may lead to a free riding problem within a merged firm.

For simplicity, we only consider two extreme cases. We start by analysing the situation where managers fully cooperate inside the firm. Managers trust each other and are willing to sacrifice their personal interests for the benefit of the firm. This setup permits us to investigate what happens when investment is a decision variable and compare it with the case where managers do not cooperate within the firm. We find that if managers inside a firm cooperate, they have more incentives to do so in a merged firm because of potential synergies. However, since they invest only when it is profitable, a potential merger is not necessarily more efficient, even when there is no internal conflict. The second scenario considers a situation where the managers do not trust each other. As a result, investment decisions are done only if it is beneficial for the manager personally (or for his team). As argued before, these decisions are often not contractible while a firm's profit is easy verifiable and thus contractible. Thus suboptimal investment decisions are likely to occur (Holmström [15]). We find that the conflict of interests within the firm can dominate the possible synergies, making a larger merged firm invest less. A merger can therefore even be a less efficient firm than non-merged firms. One can think of a more rich and realistic model where managers are not fully cooperating nor in full distrust, but somewhere in between potential outside buyers. Hart and Holmstrom [14] present a model in which workers receive private benefits from firm policies, which may or may not be aligned with owners' benefits because a worker's job satisfaction may differ from what owners want them to do. Mailath et al. [19] posit that the value of a manager's human capital depends on the firm's business strategy. The resulting interaction between business strategy and managerial incentives affects then the organisation of business activities. 
these two extremes. The results of such a model should be close the model we present here, but with an intermadiate degree of moral hazard. Equivalently, a world where managers do not fully cooperate internally but investment decisions are partly contractible, would lead to a model with an intermediate degree of moral hazard.

The equilibrium investment decisions have an impact on the stability of industry structures. When looking at which mergers will effectively materialise, we find for cooperating managers inside the firm a result in the spirit of Salant et al. [26]: if all managers simultaneously can choose to go to the monopoly industry structure, they will do so. Thus, when managers cooperate at the investment-decision level, the only stable structure is the monopoly. However, this complete market concentration does not necessarily lead to a more efficient production. For noncooperating managers, not only the monopoly structure but the duopoly and triopoly are also possible stable outcomes. Two conclusions follow. First, conflict within the firm can lead to less market concentration, even when mergers lead potentially to more efficient firms. Second, when there will indeed be mergers in equilibrium, these merged firms are sometimes to be found less efficient. This happens when -despite the internal conflict- it is optimal to merge, but -because of more internal conflict and aggressive investment of competitors- managers invest less in the larger merged firms.

Welfare analysis says us three things. First, taking efficiency gains as exogenous would lead to the approval of many mergers that are welfare reducing. Second, this approving of welfare reducing mergers is done more often and is more costly when managers do not cooperate internally. And third, when using total welfare as a welfare measure instead of consumer welfare, mistakes are also made more often. This calls for caution in allowing firms to defend a merger on the base of efficiency gains. Especially in situations where information about costs and gains of investing is difficult to verify, it may be better to not let firms use this argument. It must be mentioned that sometimes a merger is mistakenly prohibited when taking into account only consumers, but this mistake is intuitively less costly than the opposite one. Allowing too many mergers leads to more concentration, while allowing too few does not have this negative effect.

We give as well an explanation for merger failures. When firms decide to go together, the organisational difficulties that this creates are often underestimated. If managers do not correctly foresee the internal problems, the new firm may not be profitable and thus resulting in a failure.

The paper is structured as follows. Section 2 describes the model. Sections 3,4 and 5 present the solution of the different stages of the model. Section 6 and section 7 discuss respectively welfare issues and some extensions of the model. All proofs are presented in the Appendix. 


\section{Model}

We consider a situation where three managers decide on their productive organisation. In a first stage, managers choose whether to set up their own firm or join forces with other managers, determining the industry structure $(\Omega)$. Three market structures can arise: monopoly, duopoly or triopoly. These industry structures are denoted, respectively, $\Omega_{M}=\{m\}, \Omega_{D}=\{i, o\}$ and $\Omega_{T}=\left\{t_{1}, t_{2}, t_{3}\right\}$, where $m$ stands for a monopoly firm, $i$ for a two-manager firm in the duopoly (set up by the two "insiders"), o for a single-manager firm in the duopoly (managed by the "outsider") and $t$ for triopolist. In the second stage, production costs are determined. Each manager decides to which extent he makes a costly investment to reduce production costs. In the third stage the formed firms compete à la Cournot.

In the first stage, the merger stage, each manager decides whether to form a firm alone or together with other managers. We explain which firms merge and how merging partners share profits. We posit that the industry structure that will prevail should be stable, that is, no manager or set of managers can win by deviating form this structure. In evaluating a possible deviation, managers must make a prediction of what the other managers will do. Several ad-hoc assumptions have been followed by the literature. ${ }^{9}$ We adopt the -novel to our notice- view that the most reasonable prediction when deciding upon a deviation is that the remaining managers will choose their best strategy.

Definition 1 An industry structure $\Omega$ is stable if there is no profitable deviation by a group of managers to form another firm, considering that the remaining managers would choose to form firms to maximise their payoff.

When all three managers look to deviate from the current market structure and form a monopoly, we only need to check whether this is profitable since there are no managers left. When two managers deviate to form a two-manager firm, the remaining manager can only stay alone. More interestingly, when only one manager deviates, the remaining two optimally choose either to go together or to split apart.

\footnotetext{
${ }^{9}$ Mainly two assumptions are made in the literature. A first approach is to assume that all managers not involved in the deviation will split apart towards stand-alone firms (e.g. Barros [3]). The second way is to assume that the other managers do not react at all, which is how Horn and Persson [17] model stability.
} 
For simplicity, we present throughout the paper the case where the sharing of a firm's profits is exogenously set to giving all managers an equal part. But as argued in detail in Section 8, our results remain qualitatively unchanged when optimal contracts are used within a firm.

Once firms are formed and the market structure is set, production costs are determined in a second stage. Following Perry and Porter [21], we allow the possibility that the merged firm is larger than any of the forming firms, i.e. that it produces at lower marginal cost. We model this by assuming that each manager has a limited amount of resources or assets which, if adequately employed, lower the production cost of the firm. Hence, more managers in the firm increases the possibilities to lower the marginal cost of production. These assets also have an alternative use outside the firm and making the right asset investment for the firm implies a private cost for the manager. Thus in contrast to Perry and Porter [21], insiders do not always devote their resources to reduce the marginal costs of the merged firm. Consequently, if insiders do not invest in cost reducing activities, merged firms might not be more efficient than either of the merging firms. This allows us to differentiate between potential and realised efficiency gains.

To accommodate this additional decision, we assume that the magnitude of the investment by the managers are substracted from the common marginal cost, $S$ (instead of divided as in Perry and Porter's model). Accordingly, the constant marginal cost of firm $\omega$ in a given market structure is given by

$$
s_{\omega}=S-\sum_{j \in \omega} I_{j}
$$

where $I_{j}, I_{j} \in\{0, k\}$, represents the magnitude that investment by manager $j$ brings in lowering the production costs of firm $\omega \cdot{ }^{10}$ The cost of an investment $I_{j}$ is $C_{j}\left(I_{j}\right)$, where $C_{j}(0)=0$ and $C_{j}(k)=c$. As explained above, $c$ represents the private benefits lost by making the relationspecific investment $I_{j}$, which lowers the marginal costs by $k$ units. ${ }^{11}$ If managers' assets do not have any outside value, $c=0$, then all the managers in all possible market structures devote resources to reduce the marginal cost and our model leads to the same qualitative results as in Perry and Porter's model [21].

Managers simultaneously choose whether to make this relation-specific investment. As a

\footnotetext{
${ }^{10} \mathrm{We}$ assume that in equilibrium all firms in all industry structures produce a non-negative quantity and therefore $k \in[0,(a-S) / 2]$.

${ }^{11}$ Note that an alternative approach is to assume that the investment belongs to an interval $[0, k]$. Given the linearity of the model, this would be equivalent to the assumption $I \in\{0, k\}$ since the optimal decision on investment is always a corner solution. To consider convex cost functions for investment makes the model untractable when managers decide upon investment levels.
} 
benchmark case, in a first scenario the managers in each firm cooperatively decide which investments to make. Indeed, if there is no internal conflict within a firm, managers behave in the interest of the firm to which they belong. In the second case, each manager does what is best for him individually because of a lack of trust.

In the third stage of the game, firms simultaneously decide their production level. We consider a homogeneous market with a linear demand, $P(Q)=a-Q$, where $a$ is a positive constant measuring the size of the market and $Q=\sum_{\omega \in \Omega} q_{\omega}$ is the total production, with $q_{\omega}$ the production of firm $w .^{12}$

We solve the game by backward induction. For each scenario and for each market structure, managers take investment decisions, anticipating production decisions. Multiple Nash equilibria in investment may exist in a particular market structure. If this happens, at the merger stage managers need to make a prediction about which would be the investment outcome at that market structure. As other authors, we adopt the view that managers are optimistic: when considering a deviation leading to that structure, a manager or a group of managers predict that the resulting investment equilibrium will be the one which benefits him or them the most. Although this view may induce many deviations and no stable industry structure, it allows us to concentrate on the 'very' stable ones. ${ }^{13}$

\section{Product market competition (3rd Stage)}

Assume that an industry structure $\Omega$ with $r$ firms has been formed at stage 1 and the investments made in stage 2 imply costs $s_{v}$, for all $v \in \Omega$. Then each firm $w \in \Omega$ maximizes its profits:

$$
\max _{q_{\omega}}\left\{\left[a-\sum_{v \in \Omega} q_{v}\right] q_{\omega}-s_{\omega} q_{\omega}\right\} .
$$

\footnotetext{
${ }^{12}$ It is in the interest of all the managers in the same firm to cooperate in the product market. This is because we do not assume that there is an individual cost attached to producing. For a partnership formation model where production is costly for each manager, see Espinosa and Macho-Stadler [7].

${ }^{13}$ Diamantoudi [5] analyses the endogenous formation of coalitions using the concept of 'binding agreements' when there are multiple Nash equilibria and considers different behavioral assumptions, among others the optimistic approach. Our assumption of managers being optimistic reduces the set of stable market structures, making in some cases the set empty. In our model with three managers, stability is reached for almost all parameter combinations. Non-existence of stable outcomes is something wich unfortunately happens often when using stability concepts as for example in Horn and Persson [17]. If managers were pessimistic and hence less willing to deviate, while the set of empty structures may be smaller, we might have situations with multiple stable structures.
} 
The Nash equilibrium of the Cournot game leads firm $\omega \in \Omega$ to produce

$$
q_{\omega}=\frac{a+\sum_{v \in \Omega, v \neq \omega} s_{v}-r s_{\omega}}{r+1}=\frac{a-S-\sum_{v \in \Omega, v \neq \omega} I_{v}+r I_{\omega}}{r+1} .
$$

Without loss of generality we normalize $a-S=1$. The equilibrium (gross) profit for firm $\omega$ is

$$
\Pi_{\omega}=\frac{\left(1-\sum_{v \in \Omega, v \neq \omega} I_{v}+r I_{\omega}\right)^{2}}{(r+1)^{2}} .
$$

\section{Endogenous Investment (2nd stage)}

A manager brings in hard-to-trade assets to the firm which if adequately employed lead to lower marginal costs. When managers merge, the resulting firm might become more efficient. We say that there are efficiency gains when a merged firm produces at a lower marginal cost than would separate entities do. This lowering in marginal costs is not due to simple scale economies, but to the close integration of specific hard-to-trade assets owned by the merging managers, possibilities of "synergies" in the terminology of Farrell and Shapiro [8]. But the bringing together of these assets alone is not enough to realise synergies. It must be that managers use these assets in a productive way.

Definition 2 A merger implies efficiency gains when the merged firm produces at a lower marginal cost than would separate entities do.

We look at two extreme cases of internal organisation. First, we discuss the scenario where managers cooperate fully within the firm. This results in the best possible situation for the managers (first best). Second, the situation where profits are verifiable but investment is uncontractible, the "internal conflict" case, is looked at. This assumption is motivated by the observation that, in many circumstances, it is intrinsically hard to describe the "right" action in sufficient detail to distinguish it from many seemingly similar actions with quite different payoff consequences. Contracting to induce that action may be impossible even after the state of the world is realised. On the other hand, the monetary benefits of the firm are contractible because they are easily verifiable. Of course, other organisational set-ups are possible (see e.g. in Gal-Or [12] where different forms of integration are compared), but less adequate to describe an organisational integration where synergies can arise. 


\subsection{No Internal Conflict}

If investment is a cooperative decision within the firm, the profit for a manager $j$ in firm $\omega \in \Omega$ with $|\omega|$ managers is

$$
\pi_{\omega}^{j}=\frac{1}{|\omega|} \Pi_{\omega}-\frac{1}{|\omega|} \sum_{l \in \omega} C_{l}
$$

Note that maximizing (4) is equivalent to maximizing the (net) profits of the firm. Investment of different firms must form a Nash equilibrium.

It is intuitive enough that $\operatorname{costs} c$ and gains $k$ of investment play a major role in what happens in equilibrium and our analysis is done in function of these two parameters. But apart from costs and gains, the amount in which firms will decide to reduce production costs depends (i) on the size of the firms, i.e. the number of managers in the firm, and (ii), on the competition level. First, the larger a firm is, the more incentives to invest. Since managers in the same firm are cooperating, they will be able to exploit the synergies. Second, a firm may want to invest for strategic reasons. Investment activities are strategic substitutes across firms and more investment implies later on a better position in the production phase vis à vis the competitors. Therefore, the more competitors in the market, the more incentives a manager has to invest. This means that the scale effect and strategic effect go in opposite directions. ${ }^{14}$ Proposition 1 states the previous intuition as a function of the parameters of the model. Remark that we state the efficiency gains in the conditional state. At this stage we do not know yet which mergers are going to take place, if any.

Proposition 1 When managers cooperate, for costs w.r.t. gains of investment going from low to high, we can distinguish four regions:

(A) All managers invest. Any merger would imply efficiency gains.

(B) Managers in the monopoly and insiders in a duopoly invest, but single-manager firms may not. Any merger would imply efficiency gains.

(C) Managers that set up a firm alone do not invest. Either the monopolists or the insiders invest. There exist therefore always a merger that would lead to efficiency gains, but not any merger would lead to an efficiency gain.

\footnotetext{
${ }^{14}$ This is of course an immediate consequence of our model. The number of managers in the market is fixed, so if there are more managers inside the firm -i.e. the firm is larger- there are less managers outside the firm -ie. there are less competitors. However, it seems natural to assume that, given a certain industry, larger firms and a more concentrated market go together, even if there would be free entry.
} 
(D) Nobody invests. No merger would imply efficiency gains.

The regions defined in Proposition 1 are stated formally in the Appendix and are depicted in Figure $1 .{ }^{15}$ When the investment is free (i.e., $c=0$ ) or its costs are very low, any firm will invest in reducing production costs (region A). On the contrary, when the investment is extremely expensive as compared to the cost-production savings, the optimal decision will be not to invest (region D). For intermediate ranges of costs w.r.t. gains of investment, the synergy and strategic issues determine who invests. Region B shows that the first managers to give up investing are the one-manager firms, because the synergy event is strongest: the smallest firms loose first their incentives. In region $\mathrm{C}$, both effects can dominate. In region $\mathrm{C} 1$, only monopolists invest because the synergy effect dominates. In region $\mathrm{C} 2$, the strategic motive is more important and the insiders in the duopoly invest whereas the monopolists do not. Note that within the duopoly the insiders have more incentives to invest than the outsider because of the scale effect. In our model the strategic effects are almost always inferior to the scale effects when there is no internal conflict.

[Place Figure 1 approximately here]

Multiple investment equilibria may exist. The optimal decision for a monopoly and duopoly is always unique. In the triopoly the type of equilibrium is unique but it is not always clear which manager invests in equilibrium. There are three equilibria of the type $((k)(k)(0))$ where two managers invest, $I=k$, and the third does not. In another region of the parameters there exist three Nash equilibria where the investment decisions take the form $((k)(0)(0))$. This is because managers are ex-ante symmetric and we cannot say who invests and who not. This is not important in the investment stage, but the identity of the managers that invest or does not may be important at the merger stage.

\subsection{Internal Conflict}

We now solve the situation where managers within the firm do not cooperate when taking investment decisions. Managers choose again their investment as a function of the gains this investment implies for the profits of the firm to which they belong. But the cost of investing is not shared by the whole firm, the managers individually bear this cost and a free riding problem

\footnotetext{
${ }^{15}$ Note that the normalisation $a-S=1$ implies that $k \in[0,1 / 2]$ in order to have all firms producing in equilibrium. Without the normalisation, the axes in Figure 1 would have been: $k /(a-S)$ and $c /(a-S)$. Comparative statics with respect to $(a-S)$ would simply expand or contract the Figure.
} 
might arise. The profit for a manager $j$ in firm $\omega \in \Omega$ with $|\omega|$ managers is

$$
\pi_{\omega}^{j}=\frac{1}{|\omega|} \Pi_{\omega}-C_{j}
$$

As in the first best case, the amount in which firms decide to reduce production costs depends (i) on the size of the firms and (ii), on the competition structure. However, the issues are not as clear cut anymore. If a firm is larger, there are still more chances to exploit the synergies. But also the possibility for internal conflict grows. In a larger firm each manager receives a smaller share of the gross profits induced by his individually costly investment. The effect of the size of a firm on the incentives to invest can go both ways. Whereas for low costs with respect to gains of investment synergies dominates, conflict becomes rapidly more important as costs w.r.t. gains rise. Thus, managers in larger firms loose much faster their incentives to invest than in the case without conflict. The strategic event still induces managers in a less concentrated market to invest more. It is therefore easy to understand that both the conflict and strategic effect go in the same direction. When conflict is strong, managers in smaller firms -and therefore also facing more competitors- have more incentives to invest. Proposition 2 states the previous intuition as a function of the parameters of the model.

Proposition 2 When managers do not cooperate inside the firm, for costs w.r.t. gains of investment going from low to high, we can distinguish four regions:

(E) Managers in a monopoly and insiders invest. Any merger would imply efficiency gains.

(F) Managers in a monopoly never invest and there is always an equilibrium in which insiders invest. In the equilibrium where insiders invest, a merger towards duopoly would imply efficiency gains. A merger towards monopoly would mean an efficiency loss.

(G) Managers in the monopoly and insiders never invest, but there exists always a singlemanager firm that does. Any merger would imply efficiency losses.

(H) Nobody invests. No merger leads to efficiency gains or efficiency losses.

The regions defined in Proposition 2 are stated formally in the Appendix and are depicted in Figure 2. In region $\mathrm{E}$ where the investment is close to free, any firm invests. Within this region conflict is not important, and the synergy effect dominates, implying that the largest firms in the market have most incentives to invest. When costs rise relatively, the conflict issue, reinforced by the strategic effect, starts interfering with scale and managers in the monopoly stop investing (region F1). Further on, the conflict situation becomes more and more important, making either the insiders or the outsider in duopoly invest (region F2). The conflict effect becomes finally 
always dominant and insiders never invest anymore (region G). Finally, when the investment is extremely expensive as compared to the cost-production savings, the optimal decision for all managers will be not to invest (region $\mathrm{H}$ ).

[Place Figure 2 approximately here]

What does this imply for the efficiency gains? As long as the monopolist invests, any merger leads to a more efficient firm. From the moment that managers in the monopoly do not invest and other managers still do, a merger towards monopoly leads to efficiency losses. When also the insiders stop investing and the one-manager firm still does, any merger leads to efficiency losses. Finally, when nobody invests, a merger does not lead to any efficiency changes.

Summarising the results obtained for both scenarios, some mergers may induce efficiency gains but for this to be true a necessary condition is that the cost of the investment compared to the gains are low enough. When the internal conflict is important, a merger may even imply efficiency losses.

\section{$5 \quad$ Stable market structures (1st stage)}

Managers decide in the first stage to stay alone or go together with other managers, anticipating the investment decisions and competition in the market. We analyse the stable industry structures. We consider first the situation with no internal conflict.

\subsection{No Internal Conflict}

When managers cooperate within the firms, larger firms tend to invest more and tend to be more profitable. This makes it naturally more interesting for managers to merge. The next proposition confirms this intuition.

Proposition 3 When there is no internal conflict within firms, the monopoly is the only stable structure.

Two different processes lead the monopoly to be the only stable outcome. The first takes place because managers are able to avoid the classical outsider-problem. If a managers tries to free-ride on the others by deviating, the other two optimally split apart, making the deviation 
unprofitable. ${ }^{16}$ The other process leads managers very naturally towards the monopoly outcome, because any merger is profitable for all managers.

When the cost of investment is high with respect to its gains (region D in the corresponding Figure 1), managers do not invest and the only motive for merging is having more market power. Managers reach thus the monopoly through the first process. However, when the cost of investment is low with respect to its gains (region A), managers always prefer to invest because of synergies. Merged entities have therefore lower production costs, leading in general to more incentives to merge than when nobody invests. This situation is similar to the situation described in Perry and Porter [21], where the merged firm has lower production costs than either of the forming firms. Note, however, that for intermediate gains, managers still prefer to be an outsider over being in a monopoly, but now the other two will prefer to stay together over being alone. There will be therefore continuously a duopoly, but the formed firms are not stable. This area is depicted in Figure 3. Finally, in regions B and C, either the first or the second process makes the monopoly the only stable outcome.

[Place Figure 3 approximately here]

\subsection{Internal Conflict}

We present the stable mergers when conflict within firms happens. For the sake of presentation, we show the results separately for the four regions identified in Proposition 2. Consider first the case corresponding to Proposition $2(E)$ where the cost of investment is low with respect to its gains, making monopolists and insiders always invest.

Proposition 4 When there is internal conflict within firms and investment costs w.r.t. gains are low (monopolists and insiders always invest), the monopoly is the only stable structure.

When managers always prefer to invest, entities merge towards monopoly for exactly the same reasons as when managers always invest in the no-conflict situation. These results are depicted in the lower part of Figure 4 (equivalent to region $E$ of Figure 2).

[Place Figure 4 approximately here]

\footnotetext{
${ }^{16}$ The outsider-problem occurs when it is beneficial for all to merge towards monopoly, but it is even better to be the outsider in duopoly. This is the situation in Salant et al. [26]. In their model, where there are no synergies, merging is beneficial if the number of outsiders is low and the merging firms represent at least $80 \%$ of the total market. In our three-firm case this threshold implies the merger towards monopoly.
} 
The case corresponding to Proposition $2(F)$ is where the conflict effect starts interfering with the synergy effect, making the monopoly never investing and there is always an equilibrium in which insiders invest.

Proposition 5 When there is internal conflict within firms and costs w.r.t. gains of investment are intermediate (monopolists never invest and insiders might invest),

(a) If in equilibrium the insiders always invest, the duopoly or monopoly can be the unique stable industry structure.

(b) If in equilibrium either insiders or the outsider invest, the duopoly is the only stable structure.

Whenever the gains are high, the duopoly in which the insiders invest is the stable industry structure. The conflict effect induces the monopoly not to invest, but it is still not dominating in the two-player firm, making the insiders in the duopoly the best off (see intermediate part of Figure 4, corresponding to region F1 and F2 of Figure 2). In addition, insiders do not have incentives to split apart: the gains are high enough to prevent them to deviate to triopoly. Hence, duopoly is the stable market structure. ${ }^{17}$ Insiders obtain here a higher profit than monopolists. This is an important effect that appears with conflict. When there is no internal conflict, monopoly is always superior to being an insider in duopoly.

When gains are lower and costs of investment higher, the stability arguments are again the same as the situation where all managers invest in no-conflict (its three cases also appear here), but there is an important difference. Here the monopoly does not invest. However, even if in this region the monopoly does not invest, the reduction in competition and the lower benefits from investment make the monopoly substantially more beneficial and makes it the only stable industry structure (see region F1 and F2 of Figure 2). A merger to monopoly induces here efficiency losses.

When costs are high with respect to gains, we are in Proposition $2(G)$ and $2(H)$. The conflict effect becomes always dominant and neither monopolists nor insiders invest. When the

\footnotetext{
${ }^{17}$ In case (b), the investment Nash equilibrium in duopoly is not unique. There is an equilibrium where only the insiders invest and a second where only the outsider invests. When two managers deviate, they are optimistic and expect that in the duopoly structure the Nash equilibrium will be such that they will invest and the outsider will not. They obtain more under this market structure than under triopoly and hence the triopoly is not stable. When deviating from monopoly, the outsider being optimistic, assumes that the final equilibrium is the one in which he invests. However, when the outsider invests, the insiders prefer to break up and to deviate towards triopoly and we have no stability. For the same reason, the outsider-investing duopoly is not stable.
} 
investment is extremely expensive as compared to the cost-production savings, the optimal decision for all managers will be not to invest.

Proposition 6 When there is internal conflict within firms and costs w.r.t. gains of investment are high (only single-manager firms might invest).

(a) If only one triopolist invests, the triopoly or monopoly can be the unique stable industry structure.

(b) Otherwise, only the monopoly can be a stable industry structure.

When only one triopolist invests and gains from investment are high enough, it is clear that the triopoly will be the only stable industry structure. ${ }^{18}$ In the other cases, monopoly is stable for the same reasons as in region $D$ in Proposition 3 .

When managers do not trust each other in a newly merged firm, they are less willing to invest, making in turn a merger sometimes unprofitable. Thus, internal conflict generates less mergers. This indicates that even when numerous factors would lead to monopolisation, managers might decide not to merge because of a lack of trust. Mergers however still occur because of the monopolisation factors. The monopolisation factors are twofold in our model: possible synergies and having more market power. But the lack of trust makes managers often not investing and mergers lead in this case to efficiency losses.

\section{Merger Regulation}

The regulator should try and estimate whether the higher power enjoyed by mergers is likely or not to be compensated by efficiency gains. We assume for most of this section that the regulator maximises consumer welfare. This is consistent with the current standards used both in the US and the EU to assess mergers. ${ }^{19}$ We adopt this assumption because it describes best current practice and it has the advantage that it allows us to keep the analysis simple. Consumer welfare

\footnotetext{
${ }^{18}$ This triopolist does not want to merge with other managers because of the reinforcing conflict and strategic effects. The other two triopolists do not want to go together either. In a duopoly, the non-investing insiders are in a disadvantage with respect to the investing outsider and moreover, they have to share profits.

${ }^{19}$ In the US, the "substantial lessening of competition" test (SLC) has been interpreted that a merger is unlawful if it is likely that it will lead to an increase in price (that is, to a decrease in consumer surplus). In the EU, it is curently debated whether to switch to the SLC test or keep the current dominace test. It is less clear whether this test is closer to a consumer welfare or total welfare standard, but the wording of article 1.1.(b) of the Merger Regulation states that the Commission shall should take into account above all the interests of the consumers.
} 
in our model is defined as:

$$
W_{C}=\frac{Q^{2}}{2}
$$

The best solution for consumers is where total industry production is highest, inducing to a lowest market price for consumers. Total production is increasing in the level of competition and in firms' efficiency.

First, suppose that we are in the scenario where managers are cooperating inside firms. From the previous section we know that managers always want to merge towards monopoly. A regulator needs thus to check when he wants to prohibit a monopoly.

Proposition 7 When there is no conflict in merged firms, a more concentrated market is welfare improving for consumers only when (1) efficiencies are realized and, (2) these gains are important enough.

Figure 5 presents the consumer optimum for internal cooperation.

[Place Figure 5 approximately here]

Whether potential efficiency gains will be realized is decisive for merger regulation. If a regulator takes efficiency gains for granted because he assumes the investment $\operatorname{cost} c$ to be zero -we call him a naive regulator- he may make significant mistakes. Whenever investment gains are high enough, a naive regulator approves a merger towards monopoly (see bottom of Figure 5). However, we believe reality is more complex and investment costs should not be taken as negligible, $c>0$. From Proposition 1 we know that there are many combinations of costs w.r.t. gains of investing where a merger does not lead to efficiency gains (see regions $C$ and $D$ of Figure 1). Taking this into account makes relatively a lot more monopolies bad for consumers since market power gains of firms are not going to be compensated with efficiency gains. For costs w.r.t. gains reasonably high, a merger towards monopoly might be approved by a naive regulator while it is not accompanied with efficiency gains and the merger should then not be allowed.

Sometimes the opposite may also happen. Imagine the situation where investment costs are zero, $c=0$, and efficiency gains $k$ are high enough such that managers in all firm structures would invest, but these gains are not so high to have a monopoly or duopoly gain enough in efficiencies to offset gains in market power. A naive regulator says then no to any merger proposal. But maybe investment costs $c$ are such that triopolists do not want to invest. Then it can occur that it is actually better to allow a merger towards monopoly since relative efficiency gains of 
the merger are high enough. Thus, sometimes a merger is erroneously blocked by naive merger authorities. This type of mistake is intuitively less costly for consumers since there might be some efficiency gains foregone, but firms gain not in market power. This leads us to the following corollary:

COROLlARY 1 For managers cooperating internally, if antitrust authorities take efficiency gains of mergers for granted, they may erroneously allow both too few or too many mergers from a consumer welfare point of view.

What happens if managers do not cooperate inside the firm? Managers in larger firms may invest less than if they would do in smaller firms as we explained in the previous section. Despite investing less, managers will still mostly want to merge towards monopoly (see Figure 4).

Proposition 8 With internal conflict, a more concentrated market is welfare improving for consumers only in exceptional cases: (1) when potential synergies are very high, and (2) when these are realize despite internal conflict.

The results in Proposition 8 are summarized in Figure 6.

[Place Figure 6 approximately here]

As before, a naive regulator allows too many mergers when the potential efficiency gains are high (see the bottom of Figure 6). But in this situation he makes this mistake more often because of the internal conflict problem that becomes more serious for higher investment $\operatorname{costs} c$. Moreover, when managers do not cooperate internally, this mistake is more costly, since a merger might lead to less efficient firms as compared to the stand-alone firms as we discussed in the previous section. The other mistake -prohibiting a merger that is welfare enhancing for consumers- is still made, but less often than before; managers in larger firms invest less, making efficiency gains seldom high enough to offset higher market power. Thus:

COROLlary 2 For managers not cooperating internally, if antitrust authorities take efficiency gains of mergers for granted, they allow more often by mistake mergers as compared with the situation where managers cooperate internally, but prohibit less often by mistake mergers.

Since allowing by mistake a merger is more costly than prohibiting one by mistake, as explained above, a shortsighted regulator does more harm when there exists internal conflict. 
Let us now have a quick look at total welfare. If the regulator were to take also firm profits into account, one could employ the standard sum of consumer and producer surplus,

$$
W_{T}=\frac{Q^{2}}{2}+\sum_{w \in \Omega} \pi^{w} .
$$

Figures 7 and 8 summarized the socially optimal market structure with no conflict and with it when this measure of welfare is used.

[Place Figures 7 and 8 approximately here]

If the standard sum of consumer and producer surplus is used, then a naive regulator makes considerably more mistakes than when using consumer welfare. If there is no internal conflict, while the intended mergers towards monopoly should be now almost always accepted if efficiency gains are taken for granted (see the bottom part of Figure 7), they should be forbidden for a wide range of combinations of costs and gains. The reason is that firms gain relatively a lot more when all invest -and a naive regulator allows then more often mergers- but this investment very often does not materialise. The second type of mistakes -prohibiting a welfare enhancing merger- is not made when using total welfare.

We can derive three main conclusions from the welfare analysis. First, taking efficiency gains as exogenous would lead to the approval of many mergers that are welfare reducing. Second, these approved mergers by mistake are made more often and are more costly when managers do not cooperate internally. Third, when using total welfare as a welfare measure instead of consumer welfare, mistakes are also made more often.

\section{Merger Failures}

Our model can also provide some explanation for the common phenomenon of merger failures. Until now managers were assumed to know the exact situation within the firm. If managers cannot perfectly foresee whether there will be internal conflict within the merged firm, it is possible that wrong merger decisions are taken. Suppose that ex-ante managers merge because they expect a priori that there will be no internal conflict, but conflict does arise later on. This misjudgments might lead to a merger failure (less profits in merger than in no-merger). We have indeed found cases where the monopoly is stable under no conflict (Section 5.1) but where in a conflict situation, profits are higher with a lower market concentration (Section 5.2). Hence, 
managers not foreseeing this conflict can erroneously merge.

A similar argument applies when managers are rational but there exists uncertainty about the possibility of internal conflict. Let us assume that ex post -in the investment stage- we are in one of our two extreme cases (no conflict at all or total conflict), but ex ante -in the merger stage- managers cannot perfectly foresee what is going to happen. Thus, managers decide upon merging given their expectations. Let us denote $\operatorname{Pr}($ Conflict $)=\alpha$, and $\operatorname{Pr}($ NoConflict $)=1-\alpha$.

Once mergers have occurred, managers realise in which case they are and investment decisions are as described in Section 4. We omit the derivation of the stable structures, but the procedure is similar to the two cases presented before. The stable market structures are obtained by calculating with expected profits and are defined by the investment gains $(k)$, investment costs $(c)$ and expectations $(\alpha)$. For illustrating purposes, we depict in Figure 9 the stability results for the case $k=1 / 2$.

[Place Figure 9 approximately here]

When managers merge to monopoly because they expect the merger to be profitable (the risk of internal conflict is sufficiently low) but there arises a conflict later, there are cases where triopoly or duopoly would have been better choices. ${ }^{20}$

It is worth noting that a complementary approach is to consider that uncertainty may affect the incentives to merge (see e.g. Banal-Estañol [2]). In addition, uncertainty over the ability of the merging firms to achieve efficiency gains may affect the behaviour of the outsiders. Amir et al. [1] model the post-merger situation as a Cournot oligopoly wherein the outsiders face uncertainty about the merged entity's final cost. In an exogenous model they consider the incentive for firms to merge and they show that bilateral mergers are profitable provided that the non-merged firms believe that the merger will achieve large enough efficiency gains, even if these gains do not materialise ex-post.

\section{Endogenous sharing rules}

Throughout the paper we considered the sharing rule as exogenous. In this section we want to highlight that our results qualitatively remain unchanged in a model where the managers optimally decide upon the sharing of the profits when the firm is formed.

\footnotetext{
${ }^{20}$ The opposite can also be true. If managers have a priori pessimistic expectations about the degree of internal conflict and choose not to merge, it may well be ex post that a merger would have been profitable.
} 
It seems natural to assume that when managers are ex ante identical, all have to receive expost the same payoff when being in the same firm. This is indeed true when there is no conflict because the sharing rule has no incentive effects (or when there is conflict but the investment cost is zero, $c=0)$. Each share is then determined by the managers' bargaining power and, since identical managers have the same bargaining power, they share profits equally. ${ }^{21}$ However, in a situation of internal conflict where assets are hard-to-transfer, the form of the sharing scheme -whether the managers receive their payoff via a fixed fee and/or as a percentage of the joint profit- determines the incentives to invest. Managers determine the terms of the contract in order to maximise the firm's profits while taking into account the incentives that this agreement provides. We state the optimal contracts for monopoly.

Lemma 1 For given gains from investment, the optimal sharing scheme that managers in a monopoly will agree on is:

(a) For very low costs of investment, the optimal sharing is the equal division of profits. Investment will reach a level $3 k$.

(b) For higher costs, one manager will receive a fixed fee and two managers will equally share the monopoly profits (minus the fixed part for the first). Investment will be $2 k$.

(c) For still higher costs, a manager is the residual claimant of the firm, and the other two managers will receive a fixed fee. Investment will be $k$.

(d) For very high costs of investment, any sharing scheme including the equal sharing of profits, will be optimal. Investment is equal to zero.

Thus, when the parameter combinations are such that agreeing on an equal sharing of the profits induces the same investment decision as in the non-conflict case, this sharing rule is optimal. When the equal sharing does not give the right incentives in a multi-manager firm, better investment incentives can be obtained by increasing the percentage of the profits to some managers and compensate the others via a fixed fee. However, in this case the potential synergies will be smaller since the managers receiving a fix payoff will not invest.

The firm formed by two managers under duopoly has a similar payment scheme: for low costs equal sharing of duopoly profits is optimal. For higher costs, a manager receives a fixed fee and the other as residual claimant will be the only one to invest. For still higher costs no manager will invest and equal sharing is again optimal.

\footnotetext{
${ }^{21}$ Ray \&and Vohra [23] proved that in a sequential coalition formation game where players are identical and they decide on the coalition they form and on nthe sharing rule, equal sharing is optimal.
} 
When managers set up the optimal payment scheme within firms, the differences between the conflict and no conflict case change more gradually because in conflict the investment levels decrease now more gradually. However, our results do not change qualitatively by letting multimanager firms sign optimal contracts. We have chosen to present the exogenous sharing rule case because this reduces drastically the number of cases to consider. While having considerably more cases, the analysis of the stable structures with endogenous sharing agreements is very similar to Propositions 4, 5 and 6.

\section{Conclusion}

The purpose of this paper is to broaden the theory on horizontal mergers with efficiency gains in concentrated markets, including investment as a strategic variable and allowing for a lack of trust within the firm. This approach facilitates the understanding of why some mergers may fail to become more efficient or even fail to happen.

We construct an endogenous merger formation model with three managers simultaneously taking merger decisions. Internal problems may arise on the moment where managers decide on investing. The lack of trust and inability to identify individual contributions may result in free-riding problems and suboptimal decisions.

We find indeed that even when a merger may be potentially more efficient managers in a merged firm do not necessarily want this to happen. People in a larger firm have effectively more incentives to invest because of synergies, but only do so when this is profitable. The problems due to a lack of trust -becoming bigger in a larger firm- can even offset the possible synergies thereby making a merged firm less efficient.

Welfare analysis tells us that taking efficiency gains as exogenous lead to the approval of too many mergers that are welfare reducing. These approved mergers by mistake are made more often and are more costly when managers do not cooperate internally. And, when using total welfare as a welfare measure instead of consumer welfare, mistakes are also made more often. It must be mentioned that sometimes a merger is mistakenly prohibited when taking into account consumer welfare, but this mistake is intuitively less costly since firms maybe do not become more efficient, but gain neither in market power.

With our results, we want to point out that the recent documents on the "efficiency defence of mergers" (see European Commission Report [6]) are forgetting some essential elements. A regulator should not assume that possible efficiency gains of a merger will be realised, which 
could change the decision for approval of this merger. This calls for caution in allowing firms to defend a merger on the base of efficiency gains. Especially in situations where information about costs and gains of investing is difficult to verify, it is maybe better to not let firms use this argument. Finally, our model also gives an explanation for merger failures. When firms decide to go together, the organisational difficulties that this creates are often underestimated. If managers do not correctly foresee internal problems, they merge while this new entity is not profitable and resulting thus in a failure.

\section{Appendix}

In this section we present the explicit expressions for the different cases in the propositions and their proofs. The proofs are given following a series of lemmas. We denote for simplicity $\Pi_{j}^{m}$ the (gross) profits for each manager in monopoly when $j$ managers invest; $\Pi_{j, l}^{i}$ and $\Pi_{l, j}^{o}$ the (gross) profits for each insider and outsider manager, respectively, when $j$ insiders and $l$ outsiders invests; and $\Pi_{1, j}^{t}$ and $\Pi_{0, j}^{t}$ the (gross) profits for each triopolist when he invests and when he does not, respectively, in the case the other $j$ triopolists invest $(j=0,1,2)$. Similarly we denote $\pi^{m}, \pi^{i}, \pi^{o}$ and $\pi^{t}$ the 'net' profits for each monopolist, insider, outsider and triopolist.

\section{Proof of Proposition 1}

Within each firm, it is always optimal for the managers to choose a corner solution, where none of them invests or all of them do. Managers in a monopoly invest if and only if $c \leq \bar{c}^{m}$ where $\bar{c}^{m}$ is implicitly defined by $\Pi_{3}^{m}-\bar{c}^{m}=\Pi_{0}^{m}$. When there is competition, firms condition their investment decisions to those of the rivals. In a duopoly, insiders' decision depends on the decision of the outsider and vice versa. The insiders invest if $c \leq \bar{c}_{1}^{i}$ and if $c \leq \bar{c}_{0}^{i}$ depending, respectively, whether the outsider invest or not, where $\Pi_{2,1}^{i}-\bar{c}_{1}^{i}=\Pi_{0,1}^{i}$ and $\Pi_{2,0}^{i}-\bar{c}_{0}^{i}=\Pi_{0,0}^{i}$. Similarly, the outsider invest if $c \leq \bar{c}_{2}^{o}$ and if $c \leq \bar{c}_{0}^{o}$ depending, respectively, whether the insiders invest or not, where $\Pi_{1,2}^{o}-\bar{c}_{2}^{o}=\Pi_{0,2}^{o}$ and $\Pi_{1,0}^{i}-\bar{c}_{0}^{o}=\Pi_{0,0}^{o}$. Finally, each triopolist invests if $c \leq \bar{c}_{j}^{t}$, where $\Pi_{1, j}^{t}-\bar{c}_{j}^{t}=\Pi_{0, j}^{t}$.

Lemma 2 The relevant cutoffs are ordered as follows: $\bar{c}_{2}^{t}<\bar{c}_{1}^{t}<\bar{c}_{0}^{t}<\bar{c}^{i} ; \bar{c}^{o}<\bar{c}^{i} ; \bar{c}_{0}^{t}<\bar{c}^{m}$ and $\bar{c}^{o}<\bar{c}^{m}$ where for simplicity we denote $\bar{c}^{i} \equiv \bar{c}_{0}^{i}$ and $\bar{c}^{o} \equiv \bar{c}_{2}^{o}$.

Proof. By definition, the cutoff points for the triopolists are $\bar{c}_{2}^{t}=\frac{3 k(2-k)}{16}, \bar{c}_{1}^{t}=\frac{3 k(2+k)}{16}$ and $\bar{c}_{0}^{t}=\frac{3 k(2+3 k)}{16}$. In a duopoly, $\bar{c}_{1}^{i}=\frac{4 k(1+k)}{9}, \bar{c}_{0}^{i}=\frac{4 k(1+2 k)}{9}, \bar{c}_{2}^{o}=\frac{4 k(1-k)}{9}$ and $\bar{c}_{0}^{o}=\frac{4 k(1+k)}{9}$. Notice 
that $\bar{c}_{0}^{o}$ is not relevant. In the region where the outsider does invest only if the insiders do not $\left(\bar{c}_{2}^{o}<c<\bar{c}_{0}^{o}\right)$, the latter always invest $\left(\bar{c}_{0}^{i}>\bar{c}_{1}^{i}=\bar{c}_{0}^{o}\right)$. Similarly, $\bar{c}_{1}^{i}$ is not relevant because when the insiders would stop investing if the outsider invested, the latter never invests. Finally, in a monopoly, $\bar{c}^{m}=\frac{k(2+3 k)}{4}$. The ordering follows from straightforward algebra.

The following Lemma characterizes the four different regions in Proposition 1.

Lemma 3 The investment decision levels are the following.

a) If $c \leq \min \left\{\bar{c}^{o}, \bar{c}_{2}^{t}\right\}$ all managers in all firms invest.

b) If $\min \left\{\bar{c}^{o}, \bar{c}_{2}^{t}\right\}<c \leq \min \left\{\bar{c}^{i}, \bar{c}^{m}\right\}$, managers in the monopoly and insiders in a duopoly invest but single-manager firms may not.

c) If $\min \left\{\bar{c}^{i}, \bar{c}^{m}\right\}<c \leq \max \left\{\bar{c}^{i}, \bar{c}^{m}\right\}$, either the insiders or the monopolists invest while the rest never does. If $k \leq \frac{2}{5}$ we have that $\bar{c}^{i} \leq \bar{c}^{m}$ and only the monopolists invest whereas if $k>\frac{2}{5}$ we have that $\bar{c}^{i}>\bar{c}^{m}$ and only the insiders invest.

d) If $c>\max \left\{\bar{c}^{i}, \bar{c}^{m}\right\}$, no manager invests.

Proof. a) and d) From Lemma 2, if $c \leq \min \left\{\bar{c}^{o}, \bar{c}_{2}^{t}\right\}$ all the cutoffs are above and hence all firms invest whereas if $c>\max \left\{\bar{c}^{i}, \bar{c}^{m}\right\}$ all the cutoffs are below and hence no manager invests.

b) In this region, by definition, the insiders and the monopolists invest. Within the region, as $c$ increases the single-manager firms stop investing gradually (in different order depending on $k)$.

c) From Lemma 2 the cutoffs for all single-manager firms are below and hence they never invest. Straightforward algebra shows that when $k \leq \frac{2}{5}$ we have that $\bar{c}^{i} \leq \bar{c}^{m}$ and therefore only the monopolists invest whereas when $k>\frac{2}{5}$ then $\bar{c}^{i}>\bar{c}^{m}$ and only the insiders invest.

This completes the proof of Proposition 1. QED.

\section{Proof of Proposition 2}

Each manager in a monopoly invests as long as $c \leq \widetilde{c}_{j}^{m}$ when $j$ other managers invest $(j=0,1,2)$, where $\Pi_{j+1}^{m}-\widetilde{c}_{j}^{m}=\Pi_{j}^{m}$. When the outsider invests in the duopoly, each insider invests if $c \leq \widetilde{c}_{j, 1}^{i}$ depending whether the other insider invests or not $(j=0,1)$ where $\Pi_{j+1,1}^{i}-\widetilde{c}_{j, 1}^{i}=\Pi_{j, 1}^{i}$. Similarly, when the outsider does not invest, the cutoff points are $\widetilde{c}_{j, 0}^{i}(j=0,1)$ with the analogous definitions. The cutoff values for the single-manager firms are the same as in the proof of Proposition $1, \widetilde{c}_{j}^{o}=\bar{c}_{j}^{o}$ and $\widetilde{c}_{j}^{t}=\bar{c}_{j}^{t}$.

Lemma 4 The relevant cutoffs are ordered as follows: $\widetilde{c}_{2}^{t}<\widetilde{c}_{1}^{t}<\widetilde{c}_{0}^{t}<\widetilde{c}_{0}^{o}$; $\widetilde{c}^{m}<\widetilde{c}_{1}^{t} ; \widetilde{c}^{m}<\widetilde{c}_{1}^{i}<$ $\widetilde{c}_{0}^{i}<\widetilde{c}_{0}^{t} ; \widetilde{c}_{2}^{o}<\widetilde{c}_{0}^{o}$ and $\widetilde{c}_{1}^{i}<\widetilde{c}_{1}^{t}$ where for simplicity we denote $\widetilde{c}^{m} \equiv \widetilde{c}_{2}^{m}$ and $\widetilde{c}_{j}^{i} \equiv \widetilde{c}_{1, j}^{i}$. 
Proof. In the monopoly structure, $\widetilde{c}_{0}^{m}=\frac{k(2+k)}{12}, \widetilde{c}_{1}^{m}=\frac{k(2+3 k)}{12}$ and $\widetilde{c}_{2}^{m}=\frac{k(2+5 k)}{12}$. We have that all the managers investing is an equilibrium whenever $c \leq \widetilde{c}_{2}^{m}$ whereas no manager investing is an equilibrium whenever $c>\widetilde{c}_{0}^{m}$. Between $\widetilde{c}_{0}^{m}$ and $\widetilde{c}_{2}^{m}$ both equilibrium coexist but the former is chosen because it Pareto dominates the latter. Then $\widetilde{c}_{0}^{m}$ and $\widetilde{c}_{1}^{m}$ are not relevant. In the duopoly structure, the cutoffs for the insiders are $\widetilde{c}_{0,0}^{i}=\frac{2 k(1+k)}{9}, \widetilde{c}_{0,1}^{i}=\frac{2 k}{9}, \widetilde{c}_{1,0}^{i}=\frac{2 k(1+3 k)}{9}$ and $\widetilde{c}_{1,1}^{i}=\frac{2 k(1+2 k)}{9}$. The same argument as in the monopoly case applies here and only the cutoffs in which the partner invests are relevant. In turn, the relevant cutoffs for the outsiders are the ones in which none or all the insiders invest. The cutoffs for the outsider and the triopolists are obtained in the proof of the previous proposition. Straightforward algebra leads to the ordering.

Lemma 5 The investment decision levels are the following.

a) If $c \leq \widetilde{c}^{m}$ the managers in the monopoly and the insiders in the duopoly invest.

b) If $\widetilde{c}^{m}<c \leq \widetilde{c}_{1}^{i}$ or $\max \left\{\widetilde{c}_{1}^{i}, \widetilde{c}_{2}^{o}\right\}<c \leq \widetilde{c}_{0}^{i}$ there is an equilibrium in which the insiders in the duopoly invest whereas the managers in the monopoly never invest.

c) If $\widetilde{c}_{1}^{i}<c \leq \min \left\{\widetilde{c}_{2}^{o}, \widetilde{c}_{0}^{i}\right\}$ and $\widetilde{c}_{0}^{i}<c \leq \widetilde{c}_{0}^{o}$ the insiders and the monopolists never invest and at least one single-manager firm invests.

d) If $c>\widetilde{c}_{0}^{o}$ nobody invests.

Proof. a) We can distinguish two subcases: a.1) When $c \leq \min \left\{\widetilde{c}^{m}, \widetilde{c}_{2}^{o}\right\}$, from Lemma 4 , all the managers invest because all the cutoffs are above. a.2) When $\widetilde{c}_{2}^{o} \leq c<\widetilde{c}^{m}$ the outsider does not invest by definition and there may be a triopolist that does not invest (when $\widetilde{c}_{2}^{t} \leq c<\widetilde{c}^{m}$ ). In other situations, all managers invest.

b) Here the monopolists stop investing. Again we can distinguish two subcases: b.1) when $\widetilde{c}^{m}<c \leq \widetilde{c}_{1}^{i}$ the insiders always invest independent of the outsider decision. From Lemma 4 , depending on the combination of parameters, the outsider may or may not invest whereas there are two or three triopolists doing so. b.2) If $\max \left\{\widetilde{c}_{1}^{i}, \widetilde{c}_{2}^{o}\right\}<c \leq \widetilde{c}_{0}^{i}$ there are two possible equilibria in the duopoly: either the insiders do invest and the outsider does not or vice versa. Again from Lemma 4 we can check that there might be one or two triopolists investing.

c) Here the insiders and the monopolists never invest. We distinguish five subcases: c.1) when $\widetilde{c}_{1}^{i}<c \leq \widetilde{c}_{2}^{t}$ the three triopolists and the outsider invest, c.2) when $\max \left\{\widetilde{c}_{2}^{t}, \widetilde{c}_{1}^{i}\right\}<c \leq$ $\min \left\{\widetilde{c}_{2}^{o}, \widetilde{c}_{1}^{t}\right\}$ or when $\max \left\{\widetilde{c}_{2}^{o}, \widetilde{c}_{0}^{i}\right\}<c \leq \widetilde{c}_{1}^{t}$ two triopolist and the outsider invest, c.3) when $\max \left\{\widetilde{c}_{1}^{t}, \widetilde{c}_{0}^{i}\right\}<c \leq \widetilde{c}_{0}^{t}$ one triopolist and the outsider invests, c.4) when $\widetilde{c}_{0}^{t}<c \leq \widetilde{c}_{0}^{o}$ only the outsider invest and c.5) when $c>\widetilde{c}_{0}^{o}$ no one invests. 
This completes the proof of Proposition 2. QED.

\section{Proof of Proposition 3}

In the following Lemma, we show that in our game we cannot have multiple stable regions when there is no conflict .

Lemma 6 For any combination of parameters, there is at most one stable structure.

Proof. Remember that we denote $\pi^{m}, \pi^{i}$ and $\pi^{o}$ the 'net' profits for each monopolist, insider and outsider (the equilibria in investment are unique). In order to consider all the possible cases in the triopoly, denote $\pi_{a}^{t} \geq \pi_{b}^{t} \geq \pi_{c}^{t}$ the net profits obtained by each triopolist. In what follows we state the conditions needed to ensure stability. The monopoly is stable when: (1) $\pi^{m} \geq \pi^{i}$ and (2) if $\pi_{b}^{t} \leq \pi^{i}$ then $\pi^{m} \geq \pi^{o}$ whereas if $\pi_{b}^{t}>\pi^{i}$ then $\pi^{m} \geq \pi_{a}^{t}$ (remember that the deviator is always "optimistic"). The duopoly is stable when (3) $\pi^{i}>\pi^{m}$ or $\pi^{o}>\pi^{m}$ and (4) if $\pi_{b}^{t} \leq \pi^{i}$ then $\pi^{i} \geq \pi^{o}$ whereas if $\pi_{b}^{t}>\pi^{i}$ then $\pi^{i} \geq \pi_{a}^{t}$. The second part of condition (4) is never satisfied $\left(\pi_{a}^{t} \geq \pi_{b}^{t}\right)$ and hence condition (4) can be rewritten as (4') both $\pi_{b}^{t} \leq \pi^{i}$ and $\pi^{i} \geq \pi^{o}$ should hold. Finally, the triopoly is stable whenever (5) $\pi_{a}^{t}>\pi^{m}$ and (6) $\pi_{b}^{t}>\pi^{i}$.

We are going to show the result by contradiction. Suppose firstly that the monopoly and the duopoly are stable at the same time. From (1) and (3), we get that $\pi^{o}>\pi^{m}$ and from (2) and (4') that $\pi^{m} \geq \pi^{o}$ and hence a contradiction. Secondly, the duopoly and the triopoly can not be simultaneously stable structures because (4') and (6) can not be satisfied at the same time. Finally, suppose that the monopoly and the triopoly are stable structures. From (2) and (6) we obtain that $\pi^{m} \geq \pi_{a}^{t}$ which is in contradiction with (5).

Thanks to the following lemma, we know that the triopoly will never be a stable structure.

LEMMA 7 Managers always prefer the monopoly to the triopoly.

Proof. Suppose firstly that the monopolists do not invest. By Lemma 2 none of the triopolists invests either. Since $\Pi_{0}^{m}=\frac{1}{12}>\frac{1}{16}=\Pi_{0,0}^{t}$ the monopoly is always preferred. Next suppose that a given manager invests both in monopoly and in triopoly. Again, the monopoly is always preferred since $\Pi_{3}^{m}=\frac{(1+3 k)^{2}}{12}>\frac{(1+3 k)^{2}}{16}=\Pi_{1,0}^{t}>\Pi_{1,1}^{t}>\Pi_{1,2}^{t}$. Last, take the case in which a manager would invest as a monopolist but not as a triopolist. He would prefer a monopoly to a triopoly in which none of the other triopolists invests when $\Pi_{3}^{m}-c>\Pi_{0,0}^{t}$ or in other words when $c<\frac{1+24 k+36 k^{2}}{48}$. This is always the case in this region since $c<\bar{c}^{m}<\frac{1+24 k+36 k^{2}}{48}$. When there are one or two other triopolists investing, the monopoly is even more preferred. 
LEMMA 8 Managers prefer the monopoly than being insiders in a duopoly.

Proof. First suppose that a given manager invests both in the monopoly and being insider in a duopoly. Since $\Pi_{3}^{m}=\frac{(1+3 k)^{2}}{12}>\frac{(1+4 k)^{2}}{18}=\Pi_{2,0}^{i}>\Pi_{2,1}^{i}$, the insiders would never deviate from a monopoly. Second, he always prefers the monopoly whenever he does not invest in either situation because $\Pi_{0}^{m}=\frac{1}{12}>\frac{1}{18}=\Pi_{0,0}^{i}>\Pi_{0,1}^{i}$. Third, take the case in which he would invest in the monopoly but not in the duopoly (from Lemma 2 the outsider does not invest in this region either). The monopoly is preferred whenever $\Pi_{3}^{m}-c>\Pi_{0,0}^{i}$ or in other words when $c<\frac{1+18 k+27 k^{2}}{36}$. This is always the case here since $c<\bar{c}^{m}<\frac{1+18 k+27 k^{2}}{36}$. Finally suppose that as an insider he would invest but not as a monopolist (again the outsider does not invest). He prefers the monopoly as long as $\Pi_{0}^{m}>\Pi_{2,0}^{i}-c$ or $c>\frac{-1+16 k+32 k^{2}}{36}$. Since $c>\bar{c}^{m}>\frac{-1+16 k+32 k^{2}}{36}$ this is always the case in this region.

Lemma 9 The monopoly is the unique stable structure when being in a monopoly is better than being an outsider $\left(\pi^{m} \geq \pi^{o}\right)$ or when insiders in a duopoly would break for triopoly $\left(\pi_{b}^{t}>\pi^{i}\right)$. Otherwise, no industry structure is stable.

Proof. Each one of these conditions, together with Lemma 7 and Lemma 8, ensure that conditions (1) and (2) in the proof of Lemma 6 are satisfied and hence the monopoly is the (unique) stable structure. We show the second statement by contradiction. Suppose firstly that these conditions are not satisfied and that the duopoly is stable. From Lemma 6 the duopoly could only be stable when the monopoly is not or in other words when $\pi_{b}^{t} \leq \pi^{i}$ and $\pi^{o}>\pi^{m}$. From Lemma 8 we have that $\pi^{m}>\pi^{i}$ and hence $\pi^{i} \geq \pi^{o}$. This contradicts the condition (4') in the proof of Lemma 6 . Secondly, from Lemma 7 the triopoly is never stable.

Lemma 10 When there is no internal conflict within firms, the monopoly is the only stable structure. No stable structure exists when $(c, k)$ are such that $k_{1} \leq k<k_{2}$ and $c \leq \bar{c}_{2}^{t}$, where $k_{1}=\frac{4 \sqrt{2}-5}{21}$ and $k_{2}=\frac{2 \sqrt{3}-3}{3}$.

Proof. We are going to prove this lemma following the four parts identified in Lemma 3:

a) We have that $\pi^{t}=\Pi_{1,2}^{t}-c>\Pi_{2,1}^{i}-c=\pi^{i}$ whenever $k<k_{1}=\frac{4 \sqrt{2}-5}{21}$ and that $\pi^{m}=\Pi_{3}^{m}-c \geq \Pi_{1,2}^{o}-c=\pi^{o}$ whenever $k \geq k_{2}=\frac{2 \sqrt{3}-3}{9}$. From Lemma 9 the monopoly is stable if $k<k_{1}$ or $k \geq k_{2}$ whereas if $k_{1} \leq k<k_{2}$ no industry structure is stable.

b) We are going to show that at least one of the two conditions in Lemma 9 is satisfied. On the one hand we show that when $k \geq \frac{1}{15}$ we have that $\pi^{m} \geq \pi^{o}$. If the outsider does invest, 
$\pi^{m}=\Pi_{3}^{m}-c \geq \Pi_{1,2}^{o}-c=\pi^{o}$ when $k \geq k_{2}$ and in particular when $k \geq \frac{1}{15}$. If the outsider does not invest, $\pi^{m}=\Pi_{3}^{m}-c \geq \Pi_{0,2}^{o}=\pi^{o}$ when $c \leq \frac{-1+34 k+11 k^{2}}{36}$. This inequality is always satisfied when $k \geq \frac{1}{15}$ and $c<\bar{c}^{i}$.

On the other hand we show that when $k<\frac{1}{15}$ we have that $\pi_{b}^{t}>\pi^{i}$. Take first the case in which no triopolist invests $\left(c>\bar{c}_{0}^{t}\right)$. We have that $\pi^{t}=\Pi_{0,0}^{t}>\Pi_{2,0}^{i}-c$ (and in particular that $\left.\pi^{t}>\Pi_{2,1}^{i}-c\right)$ whenever $c>\frac{-1+64 k+128 k^{2}}{144}$. This is always satisfied when $k<\frac{1}{15}$ and $c>\bar{c}_{0}^{t}$. Second consider the case where only one triopolist invests. From the definition of the cutoffs (see proof of Lemma 2), the outsider always invests in this region when we impose $k<\frac{1}{15}$. In addition, we have that $\pi_{b}^{t}=\Pi_{0,1}^{t}$. We have that $\pi_{b}^{t}=\Pi_{0,1}^{t}>\Pi_{2,1}^{i}-c=\pi^{i}$ whenever $c>\frac{-1+66 k+63 k^{2}}{144}$. This is always satisfied when $k<\frac{1}{15}$ and $c>\bar{c}_{1}^{t}$. Last take the case in which two triopolists invest (again here the outsider would invest). In this case $\pi_{b}^{t}=\Pi_{1,1}^{t}$ and $\pi_{b}^{t}=\Pi_{1,1}^{t}-c>\Pi_{2,1}^{i}-c=\pi^{i}$ whenever $k<\frac{\sqrt{2}-1}{6}$ and in particular when $k<\frac{1}{15}$.

c) In the part of this region where only the monopolists invest we have that $\pi^{t}=\Pi_{0,0}^{t}>$ $\Pi_{0,0}^{i}=\pi^{i}$ and hence the monopoly is the stable structure. When the insiders invest, we have that $\pi^{t}=\Pi_{0,0}^{t}>\Pi_{2,0}^{i}-c=\pi^{i}$ whenever $c>\frac{-1+64 k+128 k^{2}}{144}$. This condition is always satisfied since $c>\bar{c}^{m} \geq \frac{-1+64 k+128 k^{2}}{144}$.

d) Similar to the first part of part c), the monopoly is stable since $\pi^{t}=\Pi_{0,0}^{t}>\Pi_{0,0}^{i}=\pi^{i}$.

This completes the proof of Proposition 3. QED

\section{Proof of Proposition 4}

In this and in the following proofs we are going to use, when possible, Lemma 6 . In fact, it applies as long as there is not multiplicity of equilibria in the duopoly investment decisions. As we have seen in the proof of Lemma 5 the region (a) can be divided in two parts.

a.1) When any manager in any situation invests, the stable structures and the proofs are identical to those of Proposition 3 when everyone was investing.

a.2) The monopoly is stable because it is preferred to any other position in any other industry structure. We have that $\pi^{m}=\Pi_{3}^{m}-c>\Pi_{2,0}^{i}-c=\pi^{i}$ and that $\pi^{m}>\Pi_{1,1}^{t}-c>\Pi_{1,2}^{t}-c$ and hence managers prefer the monopoly to being insiders and being triopolists investing (independent of being two or three of them doing so). They prefer the monopoly to being outsiders when $\pi^{m} \geq \Pi_{0,2}^{o}=\pi^{o}$ or when $c \leq \frac{-1+34 k+11 k^{2}}{36}$ and the monopoly to being triopolists not investing when $\pi^{m} \geq \Pi_{0,2}^{t}$ or when $c \leq \frac{1+36 k+24 k^{2}}{48}$. These two conditions are always satisfied in this region $\left(\widetilde{c}_{2}^{o} \leq c<\widetilde{c}^{m}\right.$ ). Thus, the monopoly is stable and from Lemma 6 it is unique. 


\section{Proof of Proposition 5}

As we have seen in the proof of Lemma 5 this region can be divided in two parts.

b.1) Here the uniqueness result still applies. Managers prefer being insiders than monopolists whenever $c \leq c_{1}(k)=\frac{-1+12 k+18 k^{2}}{36}$ : when the outsider invests $\pi^{i}=\Pi_{2,1}^{i}-c>\Pi_{0}^{m}=\pi^{m}$ precisely when $c \leq c_{1}(k)$ whereas when he does not we have that $\pi^{i}=\Pi_{2,0}^{i}-c>\Pi_{0}^{m}=\pi^{m}$ is always satisfied in this region. In addition, $\pi^{i} \geq \pi_{b}^{t}$ independent of the number of triopolists investing and of the choice of the outsider. They also prefer to be an insider than an outsider, $\pi^{i} \geq \pi^{o}$, independent of the outsider investment decision. This three conditions are necessary and sufficient to ensure duopoly stability (see proof of Lemma 6).

When $c>c_{1}(k)$, we have that managers in a monopoly do not invest whereas in any other situation all managers invest (see proof of Lemma 5). Managers prefer the monopoly to being insiders by definition. They also prefer the monopoly to the triopoly $\pi^{m}=\Pi_{0}^{m}>\Pi_{1,2}^{t}-$ $c=\pi^{t}$ and hence the triopoly is never stable. Choices between monopoly and outsider and between insider and triopoly are going to determine three different regions. Managers prefer being monopolists than outsiders whenever $c \geq c_{2}=\frac{1}{36}$ and they prefer being insiders to triopolists whenever $k \geq k_{1}$ (see proof of Proposition 3). This defines three regions because: (a) $c_{1}^{\prime}(k)>0$ and the $k^{*}$ such that $c_{1}\left(k^{*}\right)=\widetilde{c}_{1}^{i}\left(k^{*}\right)$ is larger than the $k^{* *}$ such that $c_{2}=\widetilde{c}_{1}^{i}\left(k^{* *}\right)$ and (b) the $k^{* * *}$ such that $c_{2}=\widetilde{c}_{0}^{i}\left(k^{* * *}\right)$ is larger than $k_{1}$. In the first region, when $k \leq k_{1}$, the monopoly is stable because condition (1) and the second part of (2) are satisfied. In the second region, when $k \geq k_{1}$ and $c<c_{2}$ no structure is stable. The monopoly is not stable because condition (2) is not satisfied and the duopoly is not stable because managers prefer being outsiders than insiders $\left(\pi^{o}>\pi^{m} \geq \pi^{i}\right)$ breaking condition (4'). Finally, when $c \geq c_{2}$ (and $\left.c>c_{1}(k)\right)$ the monopoly is stable because condition (1) and the first part of (2) are satisfied.

b.2) There are two different equilibria in the duopoly (Lemma 5): either the two insiders or the outsider invest. The profits in the investing equilibrium are always higher than in the non-investing one for both the insiders and the outsider $\left(\Pi_{2,0}^{i}-c \geq \Pi_{0,1}^{i}\right.$ and $\left.\Pi_{1,0}^{o}-c \geq \Pi_{0,2}^{o}\right)$. Denoting the net profits in the insiders-investing equilibrium as $\pi_{d}^{i}$ and $\pi_{d}^{o}$ and in the outsiderinvesting one as $\pi_{e}^{i}$ and $\pi_{e}^{o}$, we have that $\pi_{d}^{i}>\pi_{e}^{i}$ and $\pi_{d}^{o}<\pi_{e}^{o}$.

We restate the stability conditions in order to accommodate this multiplicity. The monopoly is stable when: (M1) $\pi^{m} \geq \pi_{d}^{i}$ and (M2) if $\pi_{b}^{t} \leq \pi_{e}^{i}$ then $\pi^{m} \geq \pi_{e}^{o}$ whereas if $\pi_{b}^{t}>\pi_{e}^{i}$ then $\pi^{m} \geq \pi_{a}^{t}$. The insiders-investing duopoly is stable when (M3) $\pi_{d}^{i}>\pi^{m}$ or $\pi_{d}^{o}>\pi^{m}$ and (M4) if $\pi_{b}^{t} \leq \pi_{e}^{i}$ then $\pi_{d}^{i} \geq \pi_{e}^{o}$ whereas if $\pi_{b}^{t}>\pi_{e}^{i}$ then $\pi_{d}^{i} \geq \pi_{a}^{t}$. The outsiders-investing duopoly is 
stable when (M5) $\pi_{e}^{i}>\pi^{m}$ or $\pi_{e}^{o}>\pi^{m}$ and (M6) if $\pi_{b}^{t} \leq \pi_{e}^{i}$ then $\pi_{e}^{i} \geq \pi_{e}^{o}$ whereas if $\pi_{b}^{t}>\pi_{e}^{i}$ then $\pi_{e}^{i} \geq \pi_{a}^{t}$. The second part of condition (M6) is never satisfied $\left(\pi_{a}^{t} \geq \pi_{b}^{t}\right)$ and hence condition (M6) can be rewritten as (M6') both $\pi_{b}^{t} \leq \pi_{e}^{i}$ and $\pi_{e}^{i} \geq \pi_{e}^{o}$ should hold. Finally, the triopoly is stable whenever (M7) $\pi_{a}^{t}>\pi^{m}$ and (M8) $\pi_{b}^{t}>\pi_{d}^{i}$.

Now we are going to show that the insiders-investing duopoly is stable. Firstly $\pi_{d}^{i}=\Pi_{2,0}^{i}-c>$ $\Pi_{0}^{m}=\pi^{m}$ whenever $c \leq \frac{-1+16 k+32 k^{2}}{36}$ which is always true in this region. Hence condition (M3) is satisfied. We also have that $\pi_{b}^{t}>\pi_{e}^{i}$ independent of having one or two triopolists investing. If there is one clearly $\pi_{b}^{t}=\Pi_{0,1}^{t}>\Pi_{0,1}^{i}=\pi_{e}^{i}$ whereas if there are two $\pi_{b}^{t}=\Pi_{1,1}^{t}-c>\Pi_{0,1}^{i}=\pi_{e}^{i}$ whenever $c \leq \frac{1+52 k+28 k^{2}}{144}$ which is always true when $c<\widetilde{c}_{1}^{t}$. Finally, the condition $\pi_{d}^{i}>\pi_{a}^{t}$ is also satisfied since $\pi_{d}^{i}=\Pi_{2,0}^{i}-c>\Pi_{1,0}^{t}-c>\Pi_{1,1}^{t}-c$ in this region (as a triopolist, it is always better to be investing). The second part of condition (M4) is satisfied and hence this structure is stable.

This is the unique stable structure. The monopoly is not stable because, as we have seen, $\pi_{d}^{i}>\pi^{m}$ in contradiction with (M1). The outsider-duopoly is not stable either because $\pi_{b}^{t}>\pi_{e}^{i}$ and hence condition (M6') does not hold. Finally, the triopoly is not stable because $\pi_{d}^{i}>\pi_{a}^{t} \geq \pi_{b}^{t}$ contradicts condition (M8).

\section{Proof of Proposition 6}

As we have seen in the proof of Lemma 5 this region (c) can be divided in five parts. Here the uniqueness result applies. Managers clearly prefer to be monopolists rather than insiders $\left(\pi^{m}=\Pi_{0}^{m}>\Pi_{0,0}^{i}>\Pi_{0,1}^{i}\right)$. We also have that $\pi_{b}^{t}>\pi^{i}$ everywhere except when there are three triopolists investing (case c.1) where this is true only when $c<c_{3}(k)=\frac{1+34 k+k^{2}}{144}$. Indeed, when there are three triopolists investing this is the condition such that $\pi_{b}^{t}=\Pi_{1,2}^{t}-c>\Pi_{0,1}^{i}=\pi^{i}$. When there are two investing we have that $\pi_{b}^{t}=\Pi_{1,1}^{t}-c>\Pi_{0,1}^{i}=\pi^{i}$ whenever $c<\frac{1+52 k+28 k^{2}}{144}$ which is always the case when $c<\widetilde{c}_{1}^{t}$. Clearly, when there is only one $\pi_{b}^{t}=\Pi_{0,1}^{t}>\Pi_{0,1}^{i}=\pi^{i}$ (the outsider always invests) and where there is none $\pi_{b}^{t}=\Pi_{0,0}^{t}>\Pi_{0,0}^{i}>\Pi_{0,1}^{i}$.

On the other hand, we have that $\pi^{m} \geq \pi_{a}^{t}$ in all cases except when there is only one triopolist investing where this is true only when $c>c_{4}(k)=\frac{-1+18 k+27 k^{2}}{48}$. Indeed, when there is only one triopolist investing this is the condition such that $\pi^{m}=\Pi_{0}^{m} \geq \Pi_{1,0}^{t}-c=\pi_{a}^{t}$ (we can check that the it is better to be the one investing). When there are two investing we have that $\pi^{m}=\Pi_{0}^{m} \geq \Pi_{1,1}^{t}-c=\pi_{a}^{t}$ whenever $c>\frac{-1+12 k+12 k^{2}}{48}$ and this is satisfied when $c>\widetilde{c}_{1}^{i}$. Therefore they also prefer the monopoly to being triopolist when the three invest. When none of the triopolists invests, clearly $\pi^{m}=\Pi_{0,0}^{m}>\Pi_{0,0}^{t}=\pi^{t}$. 
Hence in all region c) except when there are three triopolists investing and $c \geq c_{3}(k)$ or when there is one triopolist investing and $c \leq c_{4}(k)$, the monopoly is the unique stable structure. Conditions (1) and (2) in the proof of Lemma 6 are satisfied.

When there is one triopolist investing and $c \leq c_{4}(k)$ the triopoly is the unique stable structure. In this region we have seen that $\pi_{a}^{t}>\pi^{m}$ and, as before, $\pi_{b}^{t}>\pi^{i}$ satisfying conditions (5) and (6).

Finally, when there are three triopolists investing and $c \geq c_{3}(k)$ there is no stable structure. We have that $\pi^{o}=\Pi_{1,0}^{o}-c>\Pi_{0}^{m}=\pi^{m}$ when $c<\frac{1+10 k+7 k^{2}}{18}$ and $\pi^{o}=\Pi_{1,0}^{o}-c>\Pi_{0,1}^{i}=\pi^{i}$ when $c<\frac{1+16 k+16 k^{2}}{36}$. These two conditions hold when $c<\widetilde{c}_{2}^{t}$. Then, since $\pi_{b}^{t} \leq \pi^{i}$, the monopoly is not stable because it would contradict condition (2). The duopoly is not stable either because $\pi^{o}>\pi^{i}$ contradicts condition (4'). Lastly, the triopoly is not stable because we have showed that $\pi^{m} \geq \pi_{a}^{t}$, which is in contradiction with condition (5).

\section{Proof of Proposition 7}

From (6), we have that consumer welfare is maximized when total production is highest. From (2), total production is given by

$$
Q^{\Omega}=\frac{\sum_{w \in \Omega}\left(1-\sum_{v \in \Omega, v \neq \omega} I_{v}+r I_{\omega}\right)}{r+1} \text { where } \Omega=\left\{\Omega_{M}, \Omega_{D}, \Omega_{T}\right\}
$$

We are going to prove this lemma following the four parts identified in Lemma 3.

In region a) all managers would invest $\left(I_{j}=k\right.$ for any $j$ ). Hence, $Q^{\Omega_{M}}=\frac{1+3 k}{2}, Q^{\Omega_{D}}=\frac{2+3 k}{3}$ and $Q^{\Omega_{T}}=\frac{3(1+k)}{4}$. Clearly since $Q^{\Omega_{T}}>Q^{\Omega_{D}}$ for $k<\frac{1}{3}, Q^{\Omega_{T}}>Q^{\Omega_{M}}$ for $k<\frac{1}{3}$ and $Q^{\Omega_{D}}>Q^{\Omega_{M}}$ for $k<\frac{1}{3}$, we have that the optimal industry structure is triopoly when $k<\frac{1}{3}$ and the monopoly when $k \geq \frac{1}{3}$.

In the first part of region c) (i.e. when $\left.k<\frac{2}{5}\right)$ only the monopolists would invest $\left(I_{m}=k\right.$ and $I_{j}=0$ for $j \neq m$ ). Hence, we have that $Q^{\Omega_{M}}=\frac{1+3 k}{2}, Q^{\Omega_{D}}=\frac{2}{3}$ and $Q^{\Omega_{T}}=\frac{3}{4}$, and therefore the optimal structure is the triopoly for $k<\frac{1}{6}$ and the monopoly for $k \geq \frac{1}{6}$. In the second part of region c) (i.e. when $k \geq \frac{2}{5}$ ) only the insiders in the duopoly would invest $\left(I_{i}=k\right.$ and $I_{j}=0$ for $j \neq i$ ). Hence, we have that $Q^{\Omega_{M}}=\frac{1}{2}, Q^{\Omega_{D}}=\frac{2+2 k}{3}$ and $Q^{\Omega_{T}}=\frac{3}{4}$, and therefore the optimal structure is the duopoly.

In region $\mathrm{d}$ ) no manager invests $\left(I_{j}=0\right.$ for any $\left.j\right)$. Hence, since $Q^{\Omega_{M}}=\frac{1}{2}, Q^{\Omega_{D}}=\frac{2}{3}$ and $Q^{\Omega_{T}}=\frac{3}{4}$, the triopoly is the optimal industry structure. 
In region b) the monopolists and the insiders in the duopoly invest but the single firms may not $\left(I_{j}=k\right.$ for $j=m$ and $\left.j=i\right)$. We should distinguish seven different cases depending on whether the triopolists and the outsider invest. If the outsider invests, following the same process, we have that the monopoly is the optimal industry structure when $k \geq \frac{1}{3}$; the duopoly is optimal when $k<\frac{1}{3}$ and when $k \geq \frac{1}{6}, k \geq \frac{1}{9}$ or $k \geq \frac{1}{12}$ when two, one or no triopolist invest, respectively; and the triopoly is optimal otherwise.

Suppose now that the outsider does not invest. If no triopolist invests, the optimal industry structure is the monopoly when $k \geq \frac{1}{5}$, the duopoly when $\frac{1}{16}<k \leq \frac{1}{5}$ and the triopoly when $k<\frac{1}{16}$ or $k \geq \frac{1}{12}$ when two, one or no triopolist invest, respectively; and the triopoly is optimal otherwise. If one (resp. two, three) triopolist invests, the optimal industry structure is the monopoly when $k \geq \frac{1}{5}$ (resp., $k \geq \frac{1}{4}$ and $k \geq \frac{1}{3}$ ) and the triopoly when $k<\frac{1}{5}$ (resp., $k<\frac{1}{4}$ and $k<\frac{1}{3}$ ). The results are plotted in Figure 5 .

\section{Proof of Proposition 8}

Following the same procedure as in the previous proof, we can obtain the results plotted in Figure 6 .

\section{Proof of Lemma 1}

Let us denote the contract of manager $i$ by the fixed fee (that we will denote $F_{i}$ ) and the share on the profits (denoted $\epsilon_{i}$ ). Managers will determine the terms of the contract maximise the firm's profits taking into account the incentives that this agreement provides. The payoff of manager $i$ in monopoly is $F_{i}+\epsilon_{i}\left[\pi^{m}\left(I_{m}=m k\right)\right]$ for all $i$, where $F_{i}$ is the fixed fee, $\epsilon_{i}$ the share of the gross monopoly profits $\pi^{m}$ having $m$ managers in the firm investing $k$, making total investment in the firm $I_{m}=m k$. Since investment is not contractible, each manager privately bears the cost $c$ if he invests. A manager's incentives to invest also depend on the other managers' behavior. For the equal sharing rule:

* If two managers invest, the third one will do so iff $\frac{(1+3 k)^{2}}{4}-3 c k>\frac{(1+2 k)^{2}}{4} \Longleftrightarrow c<\frac{1}{6}+\frac{5}{12} k$.

* In one manager invests and the other does not, the third manager invests iff $\frac{(1+2 k)^{2}}{4}-3 c k>$ $\frac{(1+k)^{2}}{4} \Longleftrightarrow c<\frac{1}{6}+\frac{1}{4} k$.

* In none of the other two managers invest, the third one does it iff $\frac{(1+k)^{2}}{4}-3 c k>\frac{1}{4} \Longleftrightarrow$ $c<\frac{1}{6}+\frac{1}{12} k$.

Proceeding in the same way for the other possible sharing rules, and checking the total profits 
that the monopoly will get for them, we conclude that:

* For $c \in\left[0, \frac{1}{6}+\frac{5}{12} k\right)$, rewarding all managers a percentage of the profits $\left(F_{i}=0\right.$ and $\left.\epsilon_{i}=\frac{1}{3}\right)$ yields the best incentives.

* For $c \in\left[\frac{1}{6}+\frac{5}{12} k, \frac{1}{4}+\frac{3}{8} k\right)$, the optimal contracts are:

$$
\begin{aligned}
& F_{1}=\frac{1}{3}\left[\pi^{m}\left(I_{m}=2 k\right)-2 c\right] \text { and } \epsilon_{1}=0 \\
& F_{2}=F_{3}=-\frac{1}{6}\left[\pi^{m}\left(I_{m}=2 k\right)-2 c\right] \text { and } \epsilon_{2}=\epsilon_{3}=\frac{1}{2}
\end{aligned}
$$

* For $c \in\left[\frac{1}{4}+\frac{3}{8} k, \frac{1}{2}+\frac{1}{4} k\right)$ the optimal contracts are:

$$
\begin{array}{ll}
F_{1}=F_{2}=\frac{1}{3}\left[\pi^{m}\left(I_{m}=2 k\right)-c\right] & \epsilon_{1}=\epsilon_{2}=0, \\
F_{3}=-\frac{2}{3}\left[\pi^{m}\left(I_{m}=2 k\right)-2 c\right] & \epsilon_{3}=1 .
\end{array}
$$

* For $c \in\left[\frac{1}{2}+\frac{1}{4} k, \infty\right)$ no manager will invest. Then $F_{i}=0$ and $\epsilon_{i}=\frac{1}{3}$ for $i=1,2,3$ is optimal (any other sharing contract will provide to the same incentives).

\section{References}

[1] R. Amir, E. Diamantoudi and L. Xue (2003), Merger Performance under Uncertain Efficiency Gains, mimeo CORE.

[2] A. Banal-Estañol (2002), Information-Sharing Implications of Horizontal Mergers, Working Paper UAB-CSIC 544.02.

[3] P. Barros (1998), Endogenous Mergers and Size Asymmetry of Merger Participants, Economic Letters, 60 (1), pp.113-119.

[4] F. Bloch, (1995), Endogenous Structures of Association in Oligopolies, Rand Journal of Economics, 26 (3), pp. 537-556.

[5] E. Diamantoudi (2003), Equilibrium Binding Agreements under Diverse Behavioral Assumptions, Economic Theory, 22 (2), pp. 431-446.

[6] European Commission (2001), The Efficiency Defence and the European System of Merger Control, Reports and Studies of the Directorate for Economic and Financial Affairs Vol. 5. 
[7] M. Espinosa and I. Macho-Stadler (2003), Endogenous Formation of Partnerships with Moral Hazard, Games and Economic Behavior, 44, pp.162-183.

[8] J. Farrell and C. Shapiro (2001), Scale Economies and Synergies in Horizontal Merger Analysis, Antitrust Law Journal, 68, pp. 685-710.

[9] F. Flynn (2004), Identify orientations and forms of social exchange in organizations. Academy of Management Review, forthcoming.

[10] F. Fulghieri and L. Hodrick (2003), "Synergies and Internal Agency Conflicts: The Double Edged Sword of Mergers", mimeo INSEAD.

[11] S.-O. Fridolfsson and J. Stennek (2002), Why Mergers Reduce Profits and Raise Share Prices: A Theory of Preemptive Mergers, CEPR Working Paper 2357.

[12] E. Gal-Or, Flexible Manufacturing Systems and the Internal Structure of the Firm, International Journal of Industrial Organisation, 20, pp. 1061-1096.

[13] S. Goyal and J. Moraga-González (2001), R\&D Networks, Rand Journal of Economics, 32 (4), pp. 686-707.

[14] O. Hart and B. Holmström (2002), A Theory of Firm Scope, mimeo MIT.

[15] B. Holmström (1982), Moral Hazard in Teams, Bell Journal of Economics, 13 (2), pp. $324-340$.

[16] B. Holmström (1999), The Firm as a Subeconomy, The Journal of Law, Economics and Organisation, 15 (1), pp. 74-102.

[17] H. Horn and L. Persson (2001), Endogenous Mergers in Concentrated Markets, International Journal of Industrial Organisation, 19, pp. 1213-1244.

[18] E. Kandel and E. Lazear (1992), Peer Pressure and Partnerships, Journal of Political Economy Vol. 100 (4), pp. 801-817.

[19] Mailath, G., Nocke, V. and Postlewaite, A. (2003), Business Strategy, Human Capital and Managerial Incentives, mimeo University Penn.

[20] M. Motta and H. Vasconcelos (2004), Efficiency Gains and Myopic Antitrust Authority in a Dynamic Merger Game, CEPR Working Paper 4175. 
[21] M. Perry and M. Porter (1985), Oligopoly and the Incentive for Horizontal Merger, American Economic Review, 75, pp. 219-227.

[22] R. Rajan and L. Zingales (1998), Power in a Theory of the Firm, Quarterly Journal of Economics, pp. 387-432.

[23] D. Ray and R. Vohra (1999), A Theory of Endogenous Coalition Formation, Games and Economic Behavior, 26, pp. 286-336.

[24] L-H. Röller, F. Stennek and F. Verboven (2001), Efficiency Gains from Mergers, In: The Efficiency Defence and the European System of Merger Control, Reports and Studies of the Directorate for Economic and Financial Affairs Vol. 5.

[25] L-H. Röller, F. Stennek and F. Verboven (2001), Merger Control and Enterprise Competitiveness: Empirical Analysis and Policy Recommendations, In: The Efficiency Defence and the European System of Merger Control, Reports and Studies of the Directorate for Economic and Financial Affairs Vol. 5.

[26] S. Salant, S. Switzer and R. Reynolds (1983), Losses due to Merger: The effects of an Exogenous Change in Industry Structure on Cournot-Nash Equilibrium, Quarterly Journal of Economics, 98, pp. 185-199.

[27] P. Seabright (2000), Ten Years of European Merger Control: Beesley Lecture on Regulation, mimeo IDEI. 


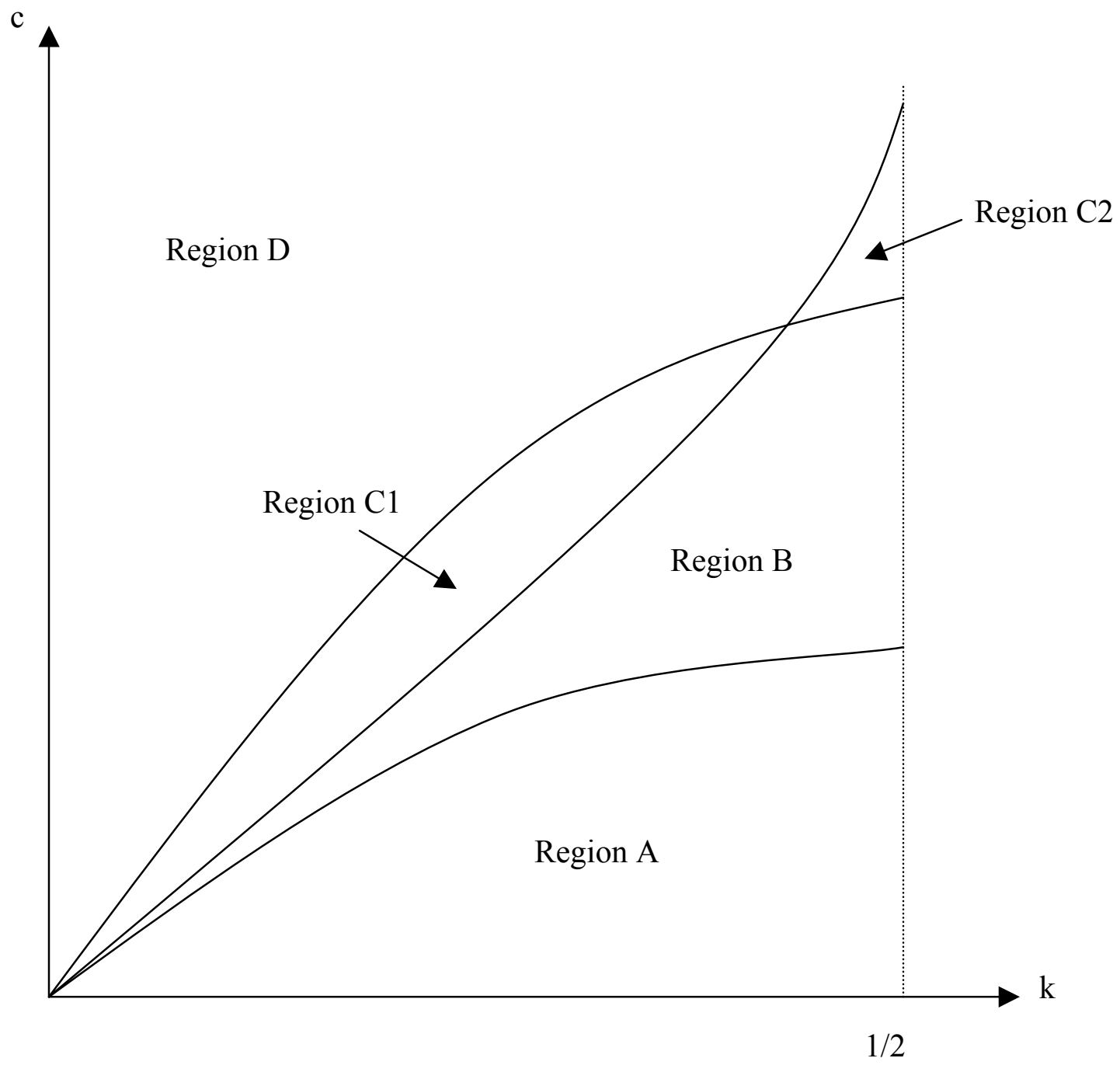

Figure 1: Investment Nash Equilibria when there is no internal conflict 


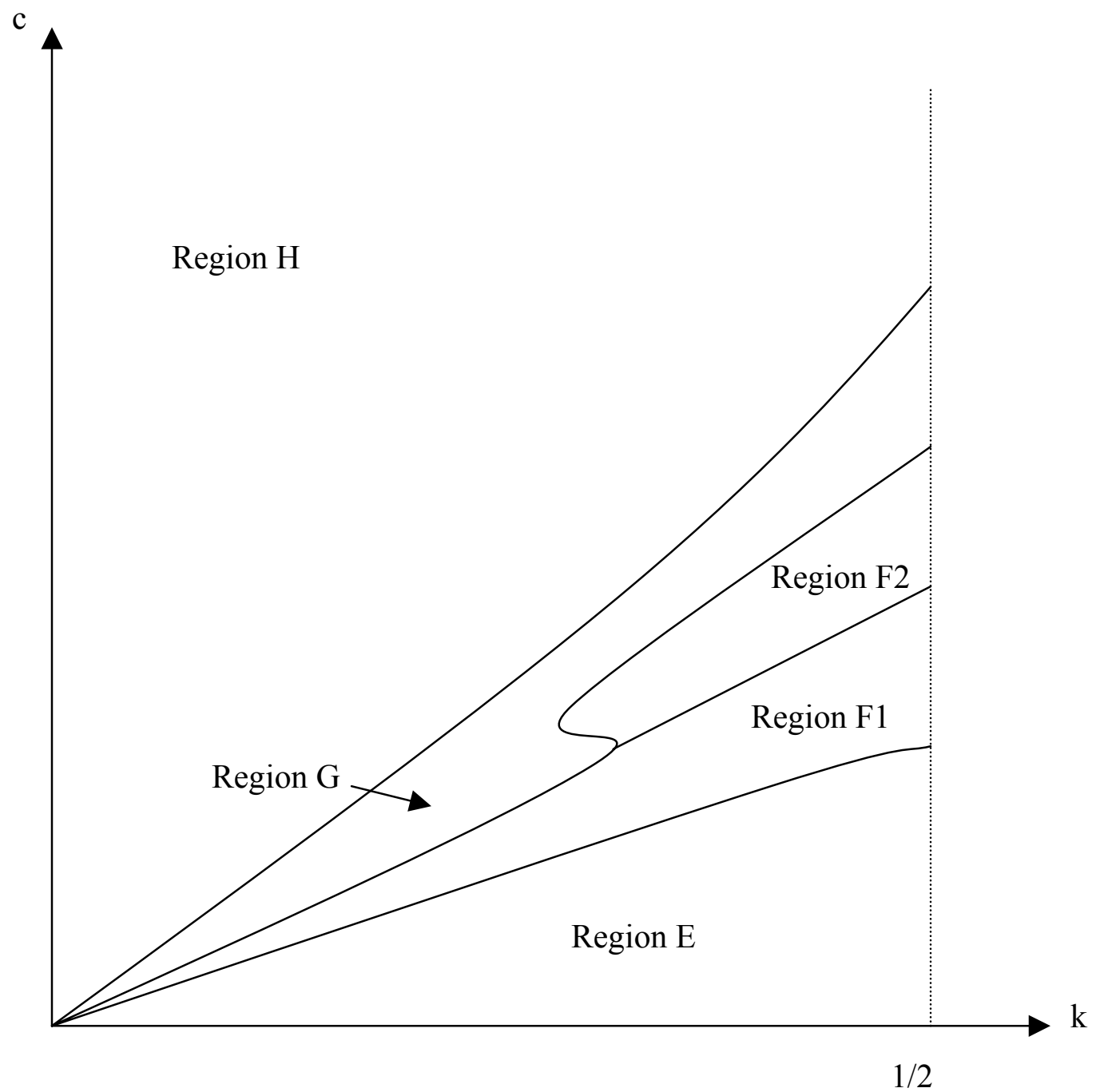

Figure 2: Investment Nash Equilibria when there is internal conflict 


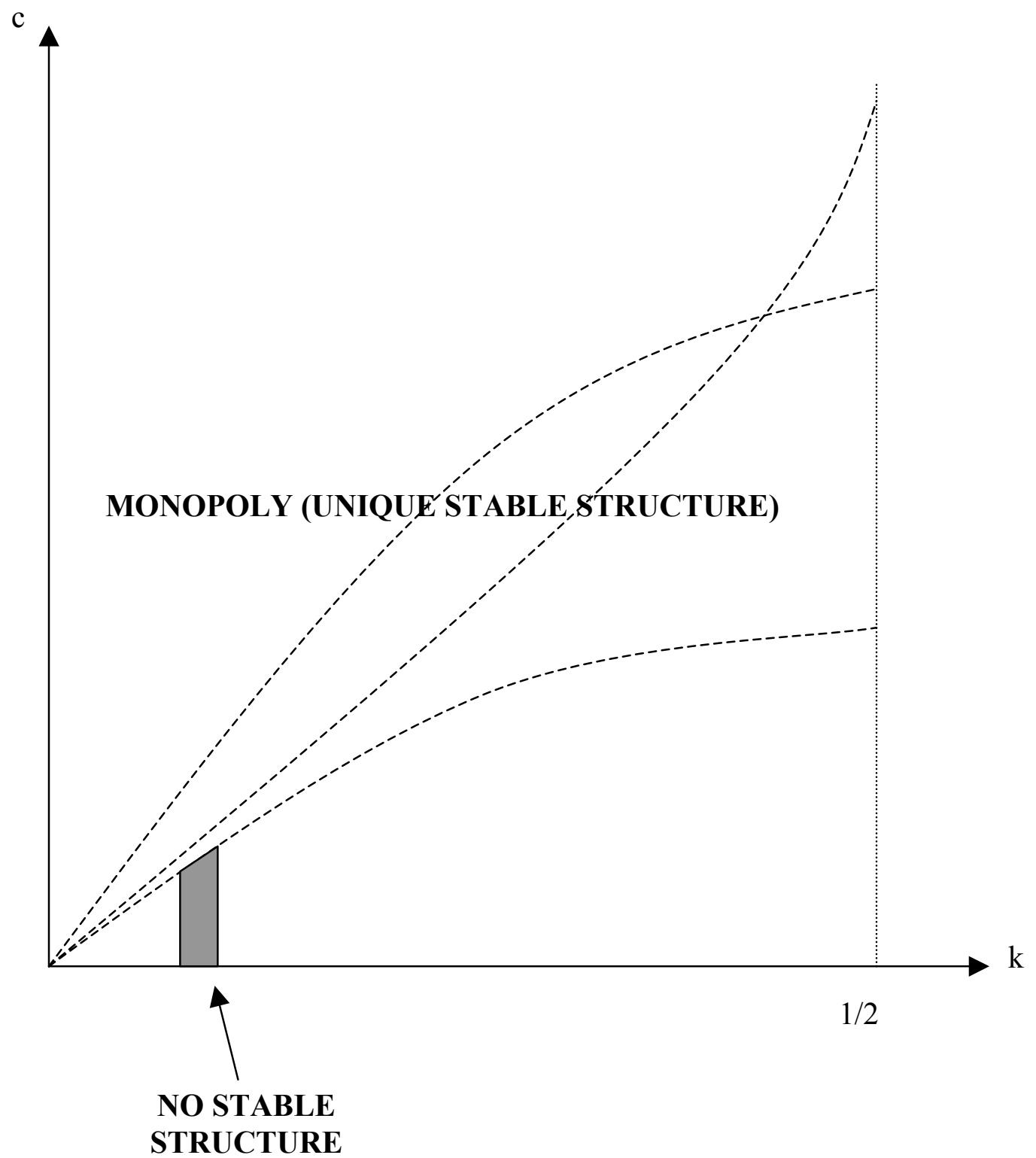

Figure 3: Stable market structures when there is no internal conflict 


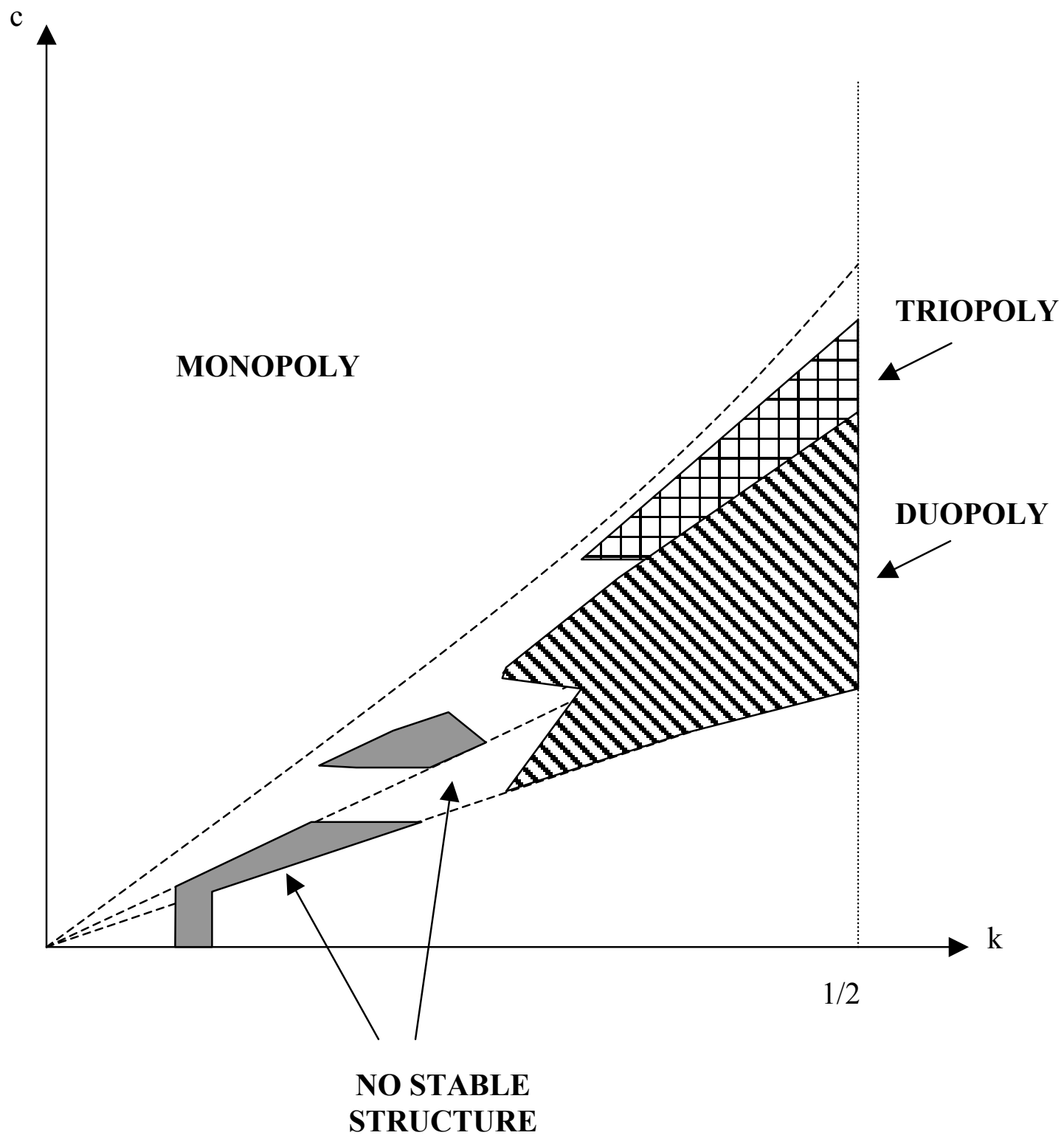

Figure 4: Stable market structures when there is internal conflict 


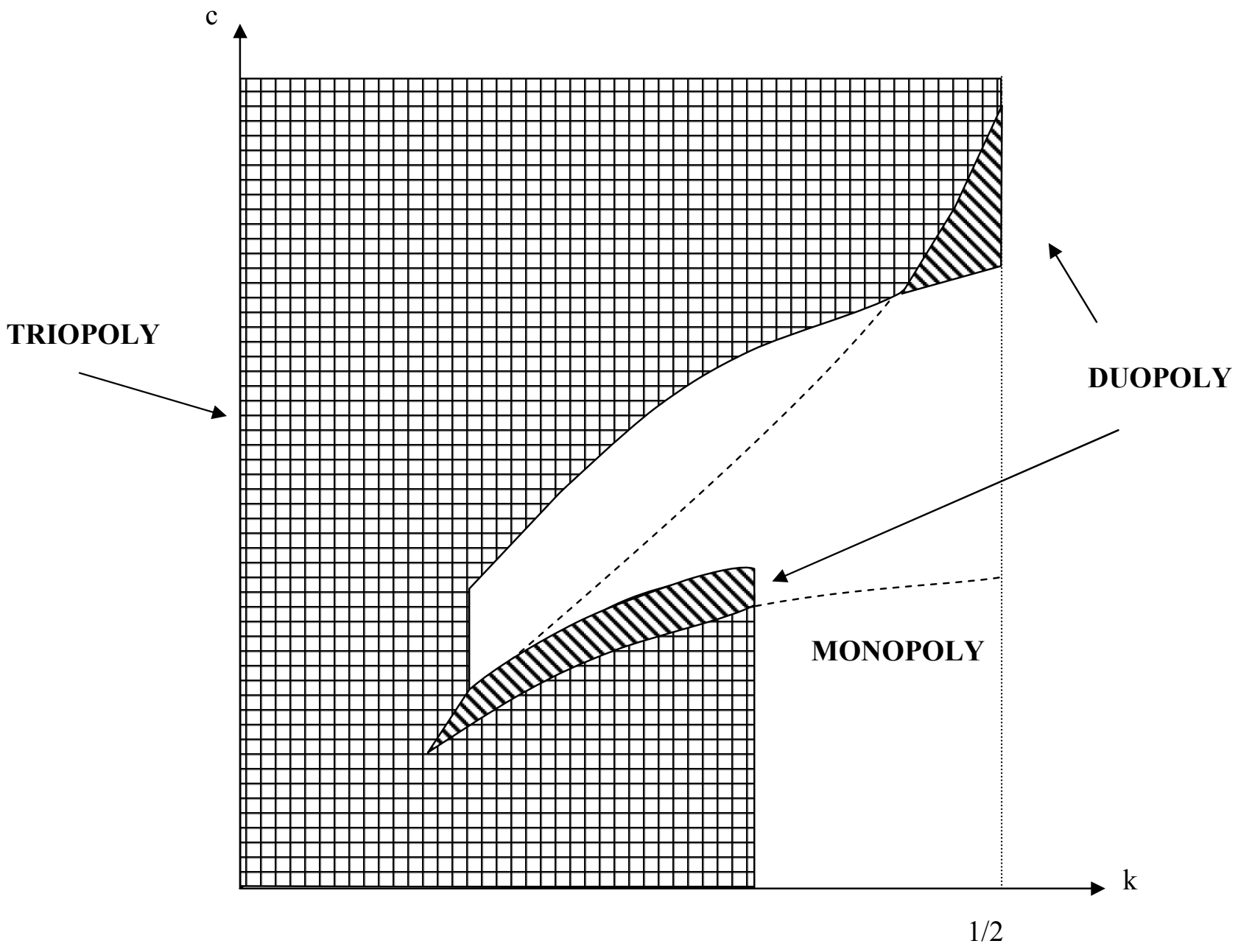

Figure 5: Consumer optimal market structures when there is no internal conflict 


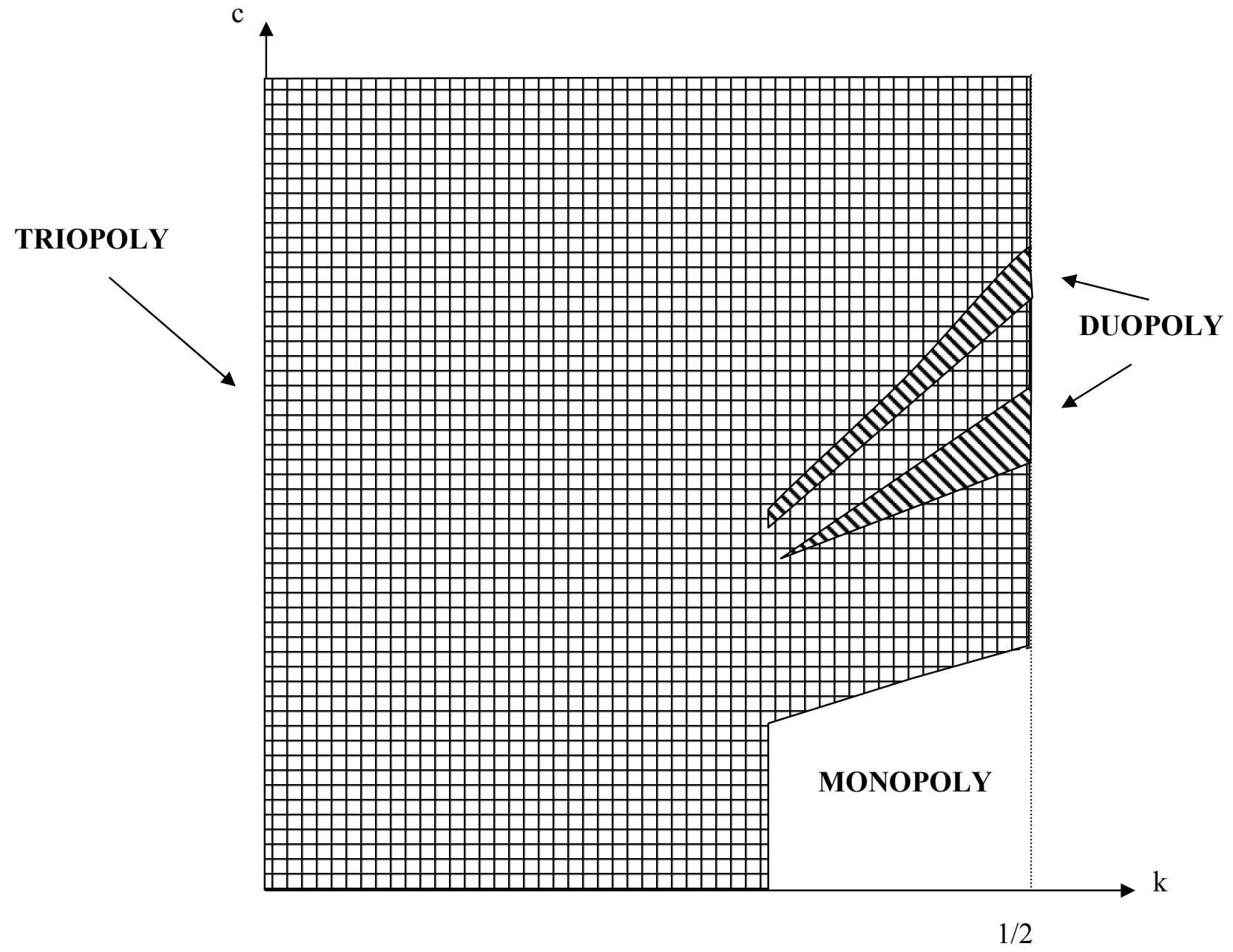

Figure 6: Consumer optimal market structures when there is internal conflict 


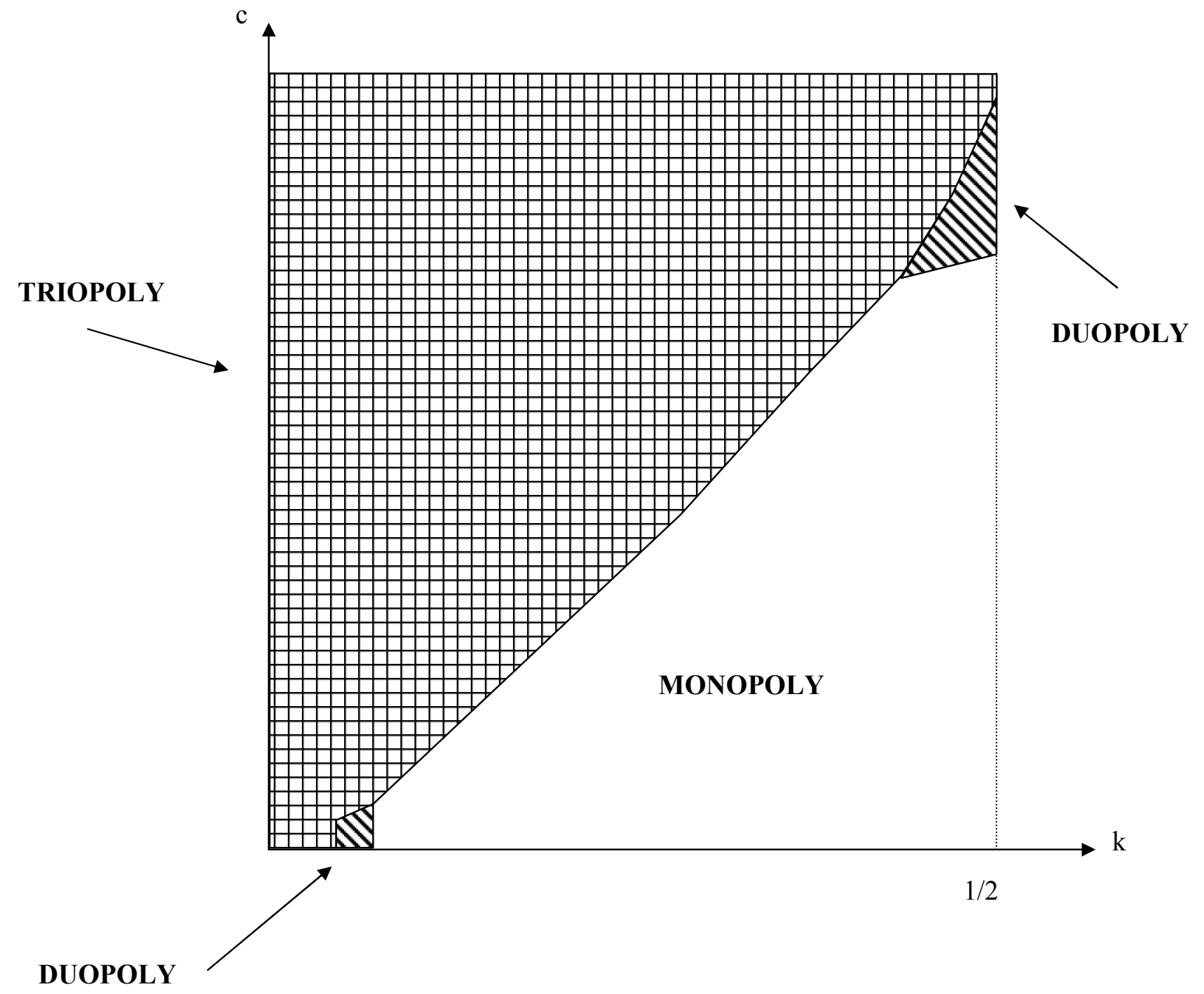

Figure 7: Socially optimal market structures when there is no internal conflict 


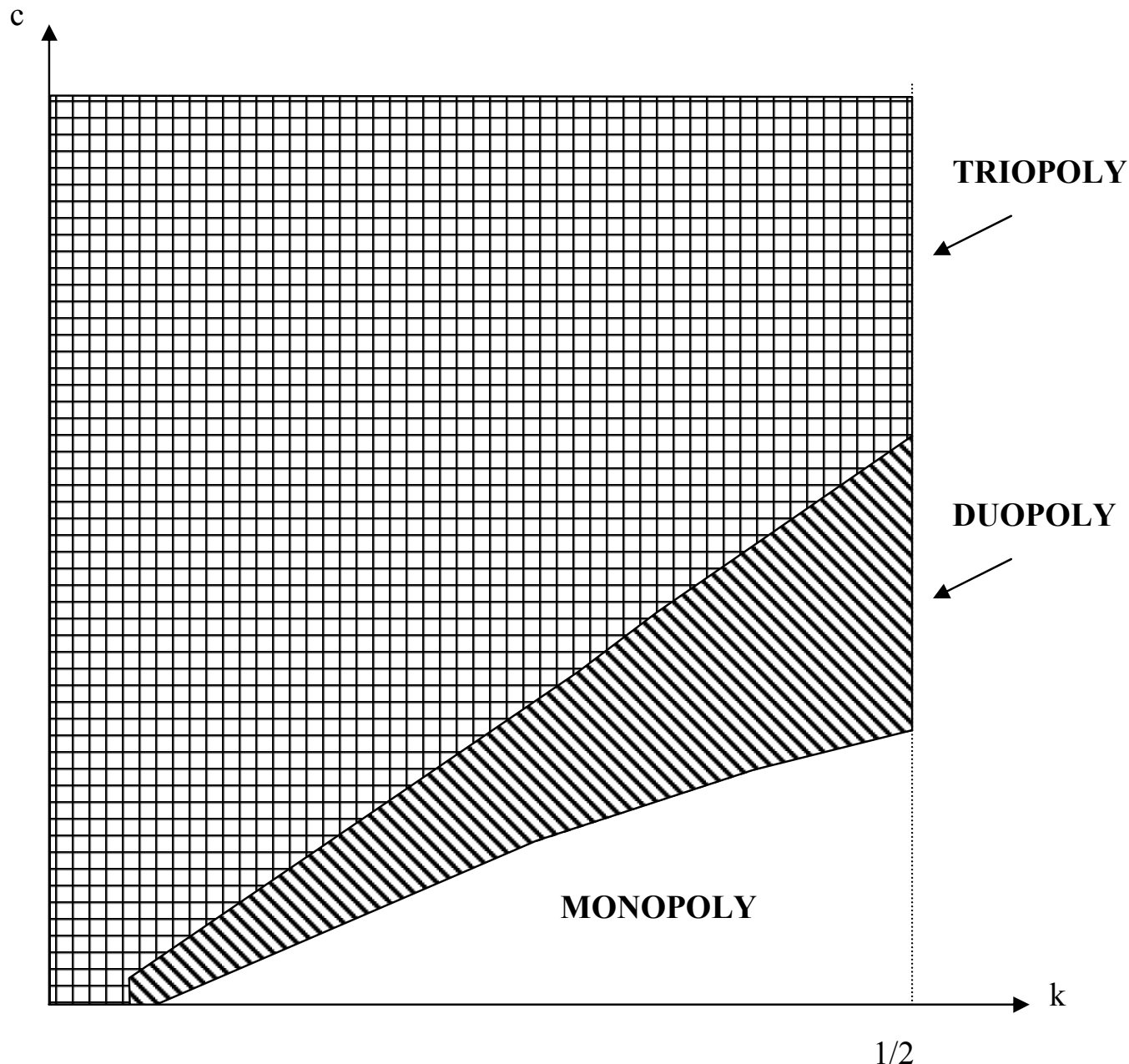

Figure 8: Socially optimal market structures when there is internal conflict 


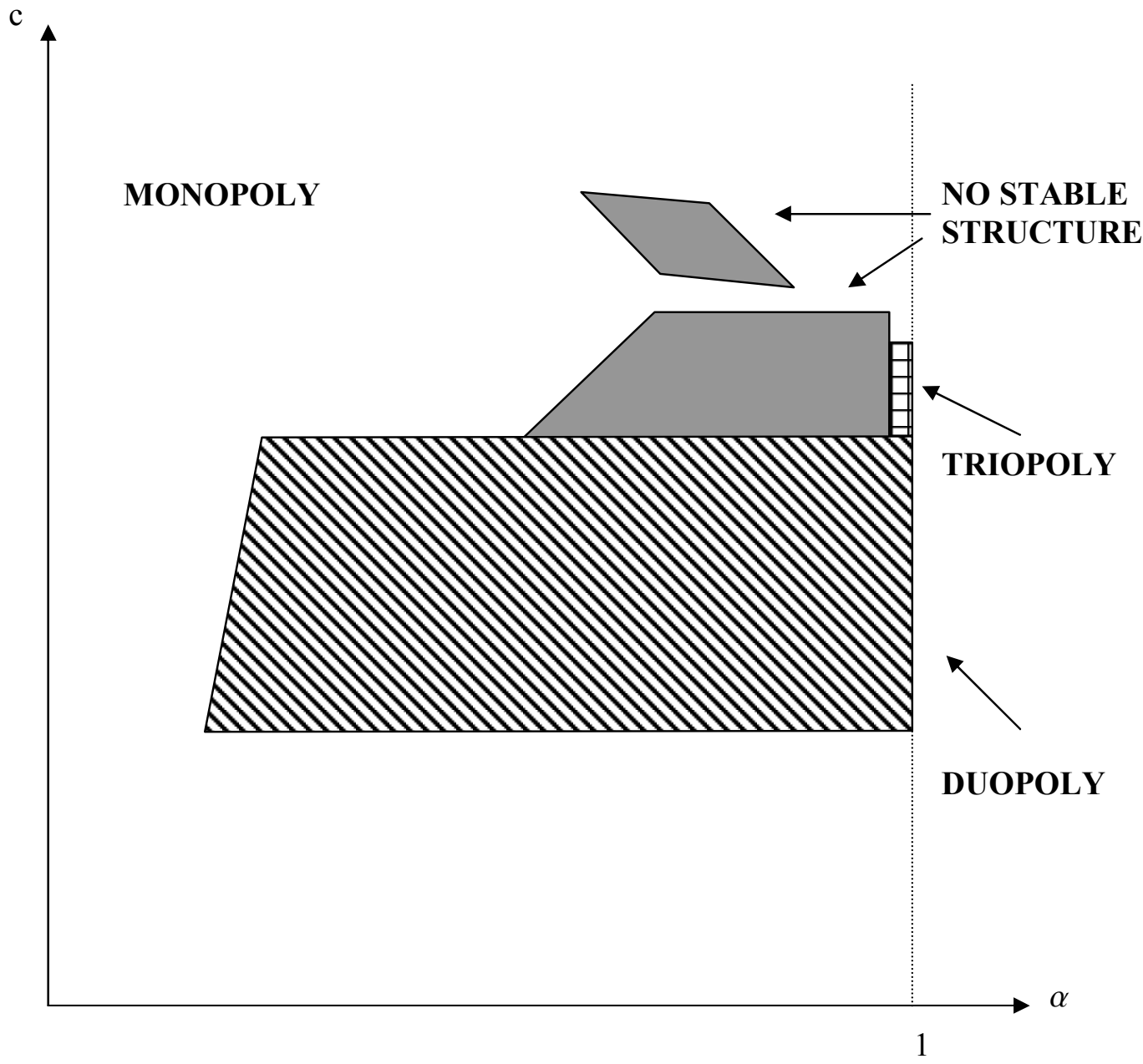

Figure 9: Stable market structures when there is

a possibility of internal conflict $(\mathrm{k}=1 / 2)$ 
Bücher des Forschungsschwerpunkts Markt und politische Ökonomie

Books of the Research Area Markets and Political Economy

Pablo Beramendi

Decentralization and Income Inequality

2003, Madrid: Juan March Institute

Thomas Cusack

A National Challenge at the Local Level: Citizens, Elites and Institutions in Reunified Germany

2003, Ashgate

Sebastian Kessing

Essays on Employment Protection

2003, Freie Universität Berlin,

http://www.diss.fu-berlin.de/2003/202

Daniel Krähmer

On Learning and Information in Markets and

Organizations

2003, Shaker Verlag

Bob Hancké

Large Firms and Institutional Change. Industrial Renewal and Economic Restructuring in France 2002, Oxford University Press

Andreas Stephan

Essays on the Contribution of Public Infrastruc-

ture to Private: Production and its Political

Economy

2002, dissertation.de

Peter A. Hall, David Soskice (Eds.)

Varieties of Capitalism

2001, Oxford University Press

Hans Mewis

Essays on Herd Behavior and Strategic Delegation

2001, Shaker Verlag

Andreas Moerke

Organisationslernen über Netzwerke - Die

personellen Verflechtungen von Führungsgremien

japanischer Aktiengesellschaften

2001, Deutscher Universitäts-Verlag

Silke Neubauer

Multimarket Contact and Organizational Design

2001, Deutscher Universitäts-Verlag

Lars-Hendrik Röller, Christian Wey (Eds.)

Die Soziale Marktwirtschaft in der neuen

Weltwirtschaft, WZB Jahrbuch 2001

2001, edition sigma

Michael Tröge

Competition in Credit Markets: A Theoretic

Analysis

2001, Deutscher Universitäts-Verlag

Torben Iversen, Jonas Pontusson, David Soskice

(Eds.)

Unions, Employers, and Central Banks

2000, Cambridge University Press
Tobias Miarka

Financial Intermediation and Deregulation:

A Critical Analysis of Japanese Bank-Firm-

Relationships

2000, Physica-Verlag

Rita Zobel

Beschäftigungsveränderungen und

organisationales Lernen in japanischen

Industriengesellschaften

2000, Humboldt-Universität zu Berlin

http://dochost.rz.hu-berlin.de/dissertationen/zobel-rita2000-06-19

Jos Jansen

Essays on Incentives in Regulation and Innovation 2000, Tilburg University

Ralph Siebert

Innovation, Research Joint Ventures, and Multiproduct Competition

2000, Humboldt-Universität zu Berlin

http://dochost.rz.hu-berlin.de/dissertationen/siebert-

ralph-2000-03-23/

Damien J. Neven, Lars-Hendrik Röller (Eds.)

The Political Economy of Industrial Policy in

Europe and the Member States

2000, edition sigma

Jianping Yang

Bankbeziehungen deutscher Unternehmen:

Investitionsverhalten und Risikoanalyse

2000, Deutscher Universitäts-Verlag

Christoph Schenk

Cooperation between Competitors -

Subcontracting and the Influence of Information, Production and Capacity on Market Structure and Competition

1999, Humboldt-Universität zu Berlin

http://dochost.rz.hu-berlin.de/dissertationen/schenkchristoph-1999-11-16

Horst Albach, Ulrike Görtzen, Rita Zobel (Eds.)

Information Processing as a Competitive

Advantage of Japanese Firms

1999, edition sigma

Dieter Köster

Wettbewerb in Netzproduktmärkten

1999, Deutscher Universitäts-Verlag

Christian Wey

Marktorganisation durch Standardisierung: Ein

Beitrag zur Neuen Institutionenökonomik des

Marktes

1999, edition sigma 
Annette Boom

Kai A. Konrad Wolfram F. Richter

Stergios Skaperdas

Johan Lagerlöf

Roman Inderst

Christian Wey

Sebastian Kessing

Robert Nuscheler

Lars Frisell

Paul Heidhues

Nicolas Melissas

Pablo Beramendi

Daniel Krähmer

Ralph Siebert

Vivek Ghosal

Vivek Ghosal

Andreas Blume

Paul Heidhues

Sebastian Kessing

Tomaso Duso Astrid Jung

Thomas R. Cusack Pablo Beramendi

Kjell Erik Lommerud Frode Meland Odd Rune Straume Joseph Clougherty
Investments in Electricity Generating Capacity under Different Market Structures and with Endogenously Fixed Demand

Zur Berücksichtigung von Kindern bei umlagefinanzierter Alterssicherung

Restraining the Genuine Homo Economicus: Why the Economy cannot be divorced from its Governance

Insisting on a Non-Negative Price: Oligopoly, Uncertainty, Welfare, and Multiple Equilibria

Buyer Power and Supplier Incentives

Monopoly Pricing with Negative Network Effects: The Case of Vaccines

The Breakdown of Authority

Equilibria in a Dynamic Global Game: The Role of Cohort Effects

Political Institutions and Income Inequality: The Case of Decentralization

Learning and Self-Confidence in Contests

The Introduction of New Product Qualities by Incumbent Firms: Market Proliferation versus Cannibalization

Impact of Uncertainty and Sunk Costs on Firm Survival and Industry Dynamics

Endemic Volatility of Firms and Establishments: Are Real Options Effects Important?

Private Monitoring in Auctions

Delay in Joint Projects

Product Market Competition and Lobbying Coordination in the U.S. Mobile

Telecommunications Industry

Taxing Work: Some Political and Economic Aspects of Labor Income Taxation

Globalisation and Union Opposition to Technological Change

Industry Trade-Balance and Domestic Merger Policy: Some Empirical Evidence from the U.S.
SP || $2003-14$

SP || $2003-01$

SP || $2003-02$

SP II $2003-03$

SP || $2003-04$

SP II $2003-05$

SP || $2003-06$

SP || $2003-07$

SP || $2003-08$

SP || $2003-09$

SP || $2003-10$

SP || $2003-11$

SP || $2003-12$

SP || $2003-13$

SP || $2003-15$

SP || $2003-16$

SP || $2003-17$

SP || $2003-18$

SP || $2003-19$ 
Dan Anderberg Fredrik Andersson

Eugenio J. Miravete Lars-Hendrik Röller

Talat Mahmood Klaus Schömann

Talat Mahmood Klaus Schömann

Suchan Chae Paul Heidhues

Sigurt Vitols

Michal Grajek

Kai A. Konrad

Helmut Bester

Kai A. Konrad

Kai A. Konrad

Kai A. Konrad

Steffen Huck Kai A. Konrad
Stratification, Social Networks in the Labour Market, and Intergenerational Mobility

Estimating Markups under Nonlinear Pricing Competition

On the Migration Decision of IT-Graduates:

A Two-Level Nested Logit Model

Assessing the Migration Decision of Indian IT-Graduates: An Empirical Analysis

Buyers Alliances for Bargaining Power

Negotiated Shareholder Value: The German Version of an Anglo-American Practice

Estimating Network Effects and Compatibility in Mobile Telecommunications

Bidding in Hierarchies

Easy Targets and the Timing of Conflict

Opinion Leaders, Influence Activities and Leadership Rents

Mobilität in mehrstufigen Ausbildungsturnieren

Moral Cost, Commitment and Committee Size
SP || $2003-20$

SP || 2003- 21

SP || $2003-22$

SP || $2003-23$

SP || $2003-24$

SP || $2003-25$

SP || $2003-26$

SP || $2003-27$

SP || $2003-28$

SP || $2003-29$

SP || $2003-30$

SP || $2003-31$ 
Jos Jansen

Johan Lagerlöf

Lars Frisell

Sigurt Vitols

Lutz Engelhardt

Antonio Guarino

Steffen Huck

Thomas D. Jeitschko

Thomas Plümper

Vera E. Troeger

Ulrich Kaisera

Pablo Beramendi Thomas R. Cusack

Joseph Clougherty

Joseph Clougherty

Anming Zhang

Roel C.A. Oomen

Robert J. Franzese,Jr. Jude C. Hays

Albert Banal-Estañol Inés Macho-Stadler Jo Seldeslachts
Partial Information Sharing in Cournot Oligopoly

Lobbying, Information Transmission, and Unequal

Representation

Changes in Germany's Bank Based Financial System: A Varieties of Capitalism Perspective

Entrepreneurial Business Models in the German Software Industry: Companies, Venture Capital, and Stock Market Based Growth Strategies of the ,Neuer Markt'

Can Fear Cause Economic Collapse?

Insights from an Experimental Study

External Effects of Currency Unions

An Estimated Model of the German Magazine Market

Diverse Disparities: The Politics and Economics of Wage, Market and Disposable Income Inequalities

Antitrust Holdup Source, Cross-National Institutional Variation, and Corporate Political Strategy Implications for Domestic Mergers in a Global Context

Export Orientation and Domestic Merger Policy: Theory and Some Empirical Evidence

Modelling Realized Variance when Returns are Serially Correlated

Modeling International Diffusion: Inferential Benefits and Methodological Challenges, with an Application to International Tax Competition

Mergers, Investment Decisions and Internal Organisation
SP || 2004-06

SP || 2004- 01

SP || 2004-02

SP || 2004-03

SP || $2004-04$

SP || $2004-05$

SP || $2004-07$

SP || 2004- 08

SP || 2004- 09

SP || 2004- 10

SP || 2004 - 11

SP || 2004- 12

SP || 2004- 13 
Bei Ihren Bestellungen von WZB-Papers schicken

Sie bitte unbedingt einen an Sie adressierten Auf-

kleber mit sowie je paper eine Briefmarke im Wert

von 0,51 Euro oder einen "Coupon Reponse Inter-

national " (für Besteller aus dem Ausland)
Please send a self addressed label and postage stamps in the amount of 0.51 Euro or a "CouponReponse International" (if you are ordering from outside Germany) for each WZB-paper requested

Absender I Return Address:

Wissenschaftszentrum Berlin

für Sozialforschung

Presse- und informationsreferat

Reichpietschufer 50

D-10785 Berlin-Tiergarten

Hiermit bestelle ich folgende(s)

Discussion paper(s):

Please send me the following Discussion paper(s):

Bestell-Nr. I Order no.

Autor/in, Kurztitel /Author(s) / Title(s) in brief 